\title{
Placebo-Induced Changes in Excitatory and Inhibitory Corticospinal Circuits during Motor Performance
}

\author{
Mirta Fiorio, ${ }^{1 \star}$ Mehran Emadi Andani, ${ }^{1,2 \star}$ Angela Marotta, ${ }^{1}$ Joseph Classen, ${ }^{3}$ and Michele Tinazzi ${ }^{1}$ \\ ${ }^{1}$ Department of Neurological and Movement Sciences, University of Verona, 37131 Verona, Italy, ${ }^{2}$ Department of Biomedical Engineering, University of \\ Isfahan, 81746-73441 Isfahan, Iran, and ${ }^{3}$ Department of Neurology, University of Leipzig, 04103 Leipzig, Germany
}

\begin{abstract}
Despite behavioral evidence showing placebo modulations of motor performance, the neurophysiological underpinnings of these effects are still unknown. By applying transcranial magnetic stimulation (TMS) over the primary motor cortex, we investigated whether a placebo modulation of force could change the excitability of the corticospinal system. Healthy human volunteers performed a motor task by pressing a piston as strongly as possible with the right index finger. Two experimental groups were instructed that treatment with peripheral low-frequency transcutaneous electrical nerve stimulation (TENS) applied on the first dorsal interosseus would induce force enhancement. One experimental group was conditioned about the effects of TENS with a surreptitious amplification of the visual feedback signaling the force level. The other group, instead, was only verbally influenced, without conditioning. At the end of the instructive placebo procedure, the two experimental groups reached higher levels of force, believed that TENS had been effective and expected to perform better compared with two control groups, who were not influenced about TENS. Moreover, the experimental groups presented enhanced excitability of the corticospinal system in the muscle specifically involved in the task (first dorsal interosseus), as shown by increased amplitude of the motor evoked potentials and decreased duration of the cortical silent period (the latter only in the conditioned group). Crucially, the TMS pulse was delivered when all the subjects exerted the same amount of force, ruling out bottom-up influences. These findings hint at a top-down, cognitive enhancement of corticospinal excitability as a neural signature of placebo modulation of motor performance.
\end{abstract}

Key words: corticospinal excitability; expectation; motor system; placebo effect; TMS

\section{Introduction}

The placebo effect is a physical or psychological benefit following the application of an inert treatment. This effect is based on the recipient's belief about the efficacy of the applied treatment and derives from expectation and learning processes (Montgomery and Kirsch, 1997; Benedetti et al., 2003). Placebo effects can be obtained not only in clinical contexts to alleviate pain or reduce motor symptoms in Parkinson's disease (de la Fuente-Fernández et al., 2001; Benedetti et al., 2003; Benedetti et al., 2004; Mercado et al., 2006; Lidstone et al., 2010; Keitel et al., 2013), but also in healthy and physiological situations to modulate motor performance (Clark et al., 2000; Beedie and Foad, 2009). For instance, well-trained cyclists who thought to have taken caffeine, increased their output in the final test compared with baseline, even though they received a placebo (Beedie et al., 2006). In a similar way, expert runners increased their speed after drinking a glass of

Received Sept. 12, 2013; revised Jan. 9, 2014; accepted Feb. 5, 2014.

Author contributions: M.F., M.E.A., J.C., and M.T. designed research; M.F., M.E.A., and A.M. performed research; M.F., M.E.A., and A.M. analyzed data; M.F., M.E.A., J.C., and M.T. wrote the paper.

We thank $G$. Negrello for help in data collection and G. Finizia and L. Bortolan for assistance in constructing the experimental apparatus.

The authors declare no competing financial interests.

${ }^{*}$ M.F. and M.E.A. have contributed equally to this work.

Correspondence should be addressed to Dr. Mirta Fiorio, Department of Neurological and Movement Sciences, University of Verona, Via Casorati, 43, 37131 Verona, Italy. E-mail: mirta.fiorio@univr.it.

DOI:10.1523/JNEUROSCI.3931-13.2014

Copyright $\odot 2014$ the authors $\quad 0270-6474 / 14 / 343993-13 \$ 15.00 / 0$ water that they thought to contain a special substance to increase endurance (Foster et al., 2004). Even in nonathletes, it is possible to influence motor performance. After a placebo procedure, untrained subjects underwent a significant decrease in perceived effort, thereby increasing the final motor performance (Pollo et al., 2008). Furthermore, after repeated administrations of morphine in the training phase, its replacement with a placebo on the day of competition increased pain endurance and physical performance (Benedetti et al., 2007).

All these studies hint at the powerful behavioral effects of placebo in influencing motor performance. However, the neurophysiological underpinnings of these effects are still completely unknown. Hence, the question arises of whether a placebo procedure in the motor domain can cause directly detectable neurophysiological changes in the nervous system of healthy subjects. It is reasonable to predict that, if placebo improves motor performance, a change should be detected in the main motor output system (i.e., the corticospinal system). The aim of this study was, therefore, to investigate the effects of placebo both on excitatory and inhibitory functions of the corticospinal system. To this purpose, during placebo procedures consisting either of verbal suggestion and conditioning or of verbal suggestion alone and efficacious to induce enhancement of force production, we applied single-pulse transcranial magnetic stimulation (TMS) over the primary motor cortex and measured the amplitude of motorevoked potentials (MEPs) as index of excitatory circuits and the 
duration of the cortical silent period (CSP) as index of inhibitory circuits. Whereas MEP amplitude is influenced by both cortical and spinal circuits (Rösler and Magistris, 2008), the CSP duration is mainly determined at the cortical level (Wolters et al., 2008). We predict that expectation of better performance, induced through a placebo procedure, can modulate the excitability of the corticospinal system, by increasing MEP amplitude and decreasing CSP duration.

\section{Materials and Methods}

\section{Participants}

A total of 60 healthy volunteers ( 29 women; mean age, $21.6 \pm 3.4$ years) were recruited from the student population of the University of Verona and were divided into four groups: 15 subjects ( 7 women; mean age, $22.3 \pm 3.1$ years $)$ entered one experimental group ( $\left.\exp _{\text {verbal }+ \text { conditioning }}\right), 15$ subjects ( 8 women; mean age, $19.9 \pm 1.03$ years) entered another experimental group ( $\left.\exp _{\text {verbal }}\right), 15$ subjects ( 7 women; mean age, $22.9 \pm 3.1$ years) entered one control group (control TENS $_{\text {) }}$, and 15 subjects ( 7 women; mean age, $21.5 \pm 5.1$ years) entered another control group ( control $_{\text {noTENS }}$ ) (see below for detailed description). The four groups did not statistically differ for age (one-way ANOVA, $F_{(3,56)}=2.38, p=0.079$ ).

All the subjects signed an informed consent form in which the experimental procedure and the TMS technique were explained in detail, before participation to the study. The local ethics committee approved the study. None of the applicants had neurological, psychiatric, or other medical problems. None of them experienced any adverse effects or complained of any discomfort during TMS. They were naive to the real purpose of the study (for description of the instructions given to the participants, see below) and were briefed about the placebo nature of the study only after completing the whole experimental procedure.

\section{Motor task}

Force production measurements were obtained by asking healthy volunteers to perform abduction movements of the right index finger to press a piston connected to a force transducer (DS BC302) (Fig. 1A). These movements are not commonly performed in daily life, and they are therefore well controlled in an experimental setting, not being contaminated by external variables, such as practice. A custom-made device was used to restrain the hand during the motor task (Fig. $1 A$; similar to Carroll et al., 2002). This tool allowed to exclude the contribution of other muscles, apart from the first dorsal interosseous (FDI) muscle, during the task. The tip of the piston was placed at $80 \%$ length of the index finger, over the distal interphalangeal joint.

Data from the force transducer were digitized by an analog-to-digital board (National Instruments, NI DAQ USB-6210) at a sampling rate of $925 \mathrm{~Hz}$ and stored in a PC for further online and offline computations (MATLAB version 7.4, MathWorks). Data were low pass filtered by maximally flat digital filtering with frequency cut at $100 \mathrm{~Hz}$ plus a 50 $\mathrm{Hz}$ notch; the filter also performed zero-phase shift digital filtering, by processing the data in both the forward and reverse directions.

Finger pressures against the piston were real-time linearly converted into vertical displacements of a cursor visible on the PC monitor. Vertical displacements $(d)$ of the cursor were calculated using the following formula:

$$
d=k \times \text { Force }
$$

where $k$ is a constant converting coefficient and Force is the pressure (in Newton, N) applied to the piston. In this way, the force exerted by the FDI determined the cursor's excursion range. Before the experimental sessions started, a calibration procedure was performed to measure the maximal force output for each subject. This calibration phase consisted of 10 trials in which subjects were asked to press the piston at their maximum voluntary force (MVF). The peak force amplitude averaged across the 10 trials was considered as the subject's MVF. This value was subsequently used by the software to scale the vertical displacements of the cursor on the PC monitor during the execution of the experiment (Fig. 1A). This procedure averted force saturation during the execution of the task and allowed for a margin of force improvement during the experiment.
At the beginning of each trial, a "START" signal appeared at the center of the monitor, and participants were asked to press the key of a mouse with the left hand to initiate the trial. After having pressed the mouse, the cursor appeared at the bottom of the monitor on a starting line representing $0 \%$ of the MVF. Participants were asked to press the piston as strongly as possible to move the cursor upward within a target zone comprising four horizontal lines of different colors, visible on the monitor. When the cursor entered the target zone, its color changed from yellow to green (Fig. 1B). Unbeknown to the subject, the lines of the target zone were displayed at $80 \%, 100 \%, 120 \%$, and $140 \%$ of the MVF (Fig. 1A). The stronger the force the subject exerted on the piston, the higher the cursor jumped on the display. In this way, the lines served as a visual feedback for the subject about the amount of applied force. This procedure was of fundamental importance to condition the subjects of the experimental group (see below). Each trial lasted $1100 \mathrm{~ms}$, and subjects were required to maintain the cursor in the achieved position until the end of the trial (Fig. 1B). The task entailed 50 trials and was repeated in three consecutive sessions (baseline, manipulation, and final; see below) executed within $1 \mathrm{~d}$. Before starting the main experiment, the subjects performed a short training of 5 trials to familiarize with the task.

\section{Procedure}

We designed a protocol consisting of three sessions: baseline, manipulation, and final (Fig. 1C). The baseline and final sessions were identical, whereas the manipulation consisted of different verbal instructions accompanied by different conditioning procedures to the experimental and control groups.

Baseline and final sessions. The baseline session consisted of the execution of the motor task as described above (50 trials). This session allowed measurement of the subjects' initial performance, before any manipulation. The final session consisted again of the execution of the motor task (50 trials) in a way identical to the baseline session. This session allowed measurement of the subjects' final performance, after the experimental manipulation.

Manipulation session. To investigate the influence of suggestion on motor performance, subjects of the experimental groups underwent a placebo procedure. Placebo responses can be induced by verbally influencing the subject's expectation of good motor output after a fake treatment. The applied treatment should have two main characteristics: (1) to be completely inert in affecting the subject's actual motor performance and, at the same time, (2) to be efficacious in inducing belief about its powerful effect on force production. To satisfy these needs, we applied 10 $\mathrm{Hz}$ transcutaneous electrical nerve stimulation (TENS) for 5 min over the hand. This type of stimulation does not have effects on motor recovery and on the corticospinal excitability, as shown instead with other durations and frequencies (Ridding et al., 2001; Mima et al., 2004; Tinazzi et al., 2005a, b; Conforto et al., 2010). TENS was delivered to the FDI muscle by an electro-stimulator with a pair of self-adhesive electrodes ( $1.5 \mathrm{~cm}$ diameter). The negative electrode was placed over the FDI muscle, and the positive electrode was placed $3 \mathrm{~cm}$ distally near the muscle. The current was an asymmetric rectangular biphasic waveform with a frequency of $10 \mathrm{~Hz}$ and a pulse width of $150 \mu \mathrm{s}$. The intensity was adjusted so that the subjects slightly felt the stimulation without muscle contraction. TENS can reasonably be expected to influence the subject's belief of good motor performance because it was directly applied over the region of the hand muscle involved in the task and caused a cutaneous sensation perceived by the subject. The experimenter paid particular attention to use appropriate expressions that could strengthen the power of verbal suggestion, such as: "This is a new treatment used also in the clinical practice that has a direct effect in enhancing force production." One experimental group $\left(\exp _{\text {verbal }}\right)$ underwent a placebo procedure consisting only of verbal suggestion about the effects of TENS in enhancing force.

Placebo effects are usually stronger if a conditioning procedure is applied together with verbal suggestion (Colloca et al., 2008). For this reason, another experimental group ( $\left.\exp _{\mathrm{verbal}+\text { conditioning }}\right)$ also underwent a conditioning procedure. To condition the subjects and reinforce their belief about the effects of the treatment, a predetermined, surreptitious magnification of the cursor's excursion was introduced stepwise. More precisely, subsequent to TENS, subjects were required to per- 
A

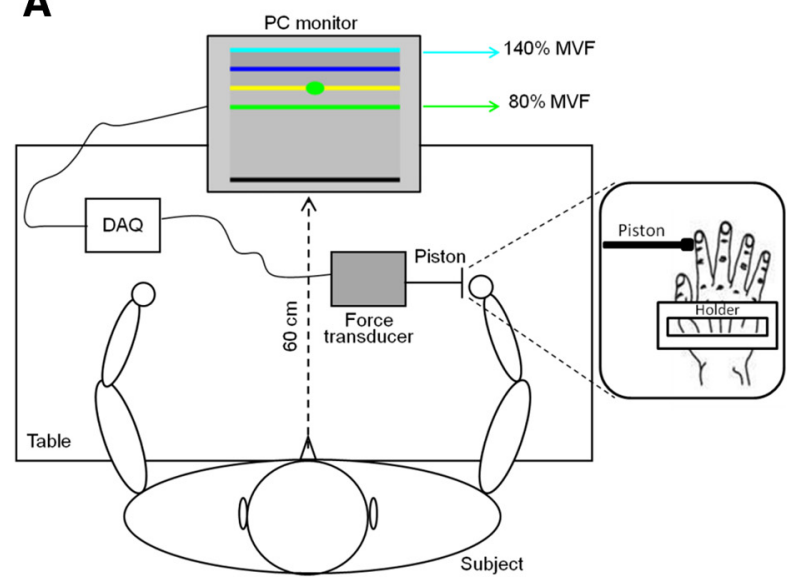

B

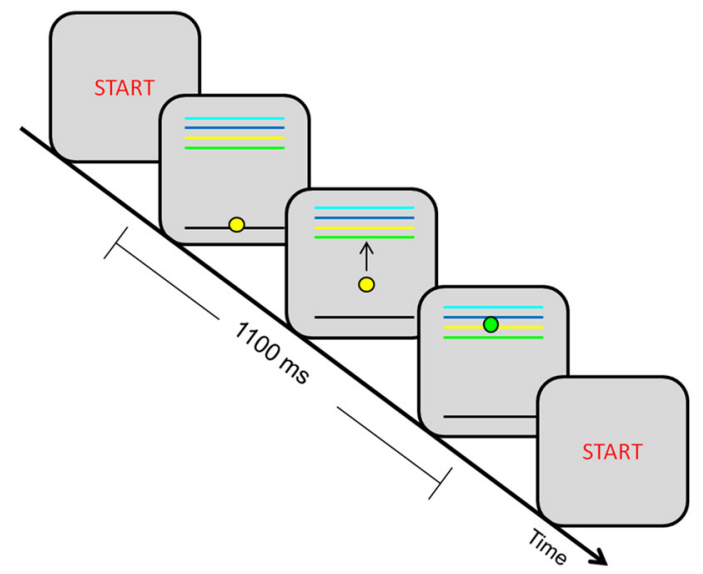

C

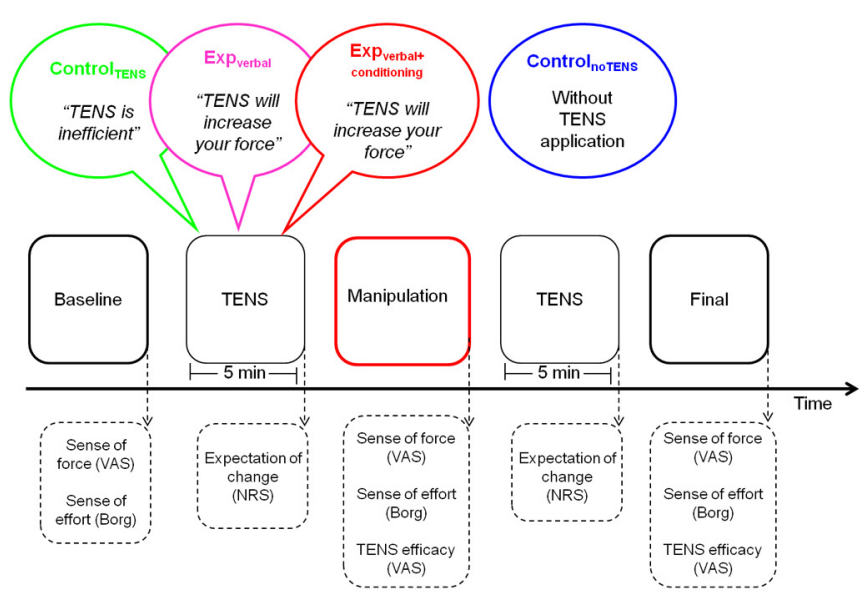

D

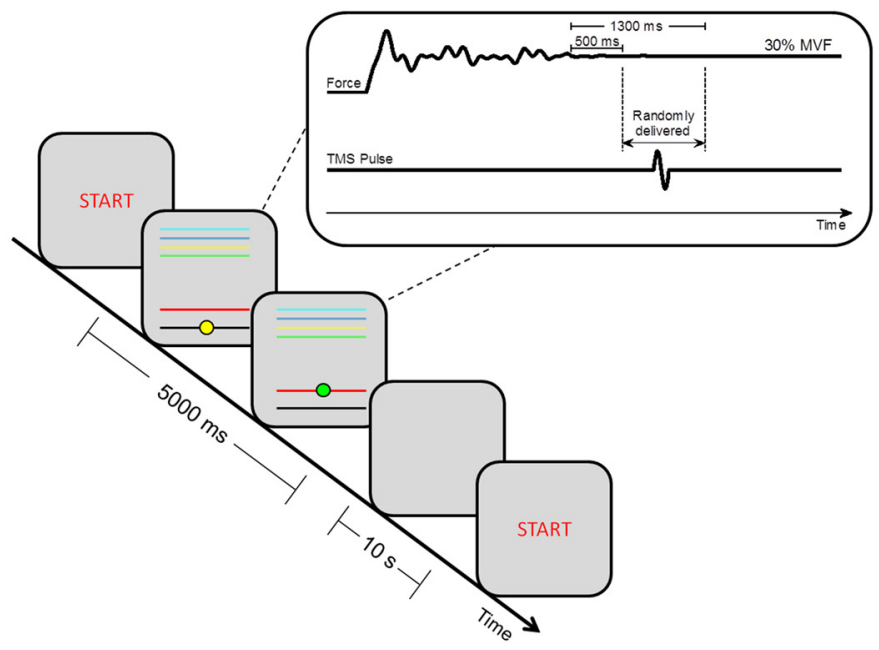

Figure 1. A, Schematic representation of the experimental setup. The subject sat comfortably at a table in front of a PC monitor displaying a starting line (black line), a target zone (colored lines), and a cursor (green dot). The lowest line of the target zone (green) represented $80 \%$ of the subject's MVF, whereas the highest line (light blue) represented 140\% of MVF, as measured for each participant in the calibration phase at the beginning of the experiment. The task was to press a piston with the right index finger as strongly as possible to reach the higher lines of the target zone. The pressures against the piston were recorded by a force transducer and converted in vertical displacements of the cursor by a DAQ board. Right, Magnified view of the hand constraint. A holder was used to keep the hand static during the performance of the motor task and to allow only movements with the index finger. $\boldsymbol{B}$, Illustration of a trial of the motor task. When the cue START appeared on the $\mathrm{PC}$ monitor, the subjects could start the trial by pressing the mouse key with the left hand. The trial started with the appearance of the black line at the bottom of the monitor, the yellow cursor, and the lines of the target zone. As soon as the subject pressed the piston, the cursor moved toward the target zone; when entering the target zone, it changed from yellow to green. Subjects had to maintain the cursor in the highest position they could achieve until the end of the trial. Each trial lasted $1100 \mathrm{~ms}$. C, Timeline of the experimental protocol with a representation of the sessions sequence (baseline, manipulation, and final) and TENS application. The dashed arrows indicate the moment at which the subjective scales were administered. As schematically shown in the picture, the control ${ }_{\text {TENS }}$ group and the two experimental groups ( $\exp _{\text {verbal + conditioning }}$ and $\left.\exp _{\text {verbal }}\right)$ received different verbal information about the effects of TENS. Moreover, in the manipulation session, the groups underwent different procedures: the $\exp _{\text {verbal + conditioning }}$ group performed the motor task with a surreptitious amplification of the cursor's excursion range (conditioning procedure), whereas the $\exp _{\text {verbal }}$ group and the control $\left.\right|_{\text {TENS }}$ group performed the motor task without any amplification. Crucial for our interest was the comparison of performance before and after manipulation (i.e., in the baseline and final sessions). An additional control group performed the motor task in the same three sessions, but without TENS application (control ${ }_{\text {notens }}$ ). D, Illustration of a trial of the TMS task. When the cue START appeared on the PC monitor, the subjects could start the trial by pressing the mouse key with the left hand. The trial started with the appearance of the black line at the bottom of the monitor, the yellow cursor, the lines of the target zone, and a red line. The red line represented the $30 \%$ of MVF as measured in the calibration phase. Subjects had to maintain the cursor on the red line until the end of the trial; because the task was not to achieve the highest lines, the lines of the target zone were dimmed compared with the motor task. Each trial lasted 5000 ms. Right, Magnified schematic view of the TMS pulse delivery is presented. If the cursor remained stable on the red line, for at least $500 \mathrm{~ms}$ (i.e., when the subject exerted a stable pressure of $30 \%$ MVF), the TMS pulse was triggered. The pulse was delivered randomly in a time window ranging from 500 to $1300 \mathrm{~ms}$ from the onset of the $30 \%$ MVF stable pressure. The TMS task was performed after the motor task, in the baseline, manipulation and final sessions. During TENS application, the electrodes for EMG recording were removed from the FDI muscle to apply the TENS electrodes. Afterward, the EMG electrodes were positioned again over the FDI muscle.

form the motor task again ( 50 trials), but this time, unbeknown to the subjects, the excursion of the cursor was progressively amplified trial by trial, with an amplification coefficient $(\alpha)$. In particular, amplified vertical displacements $\left(d^{\prime}\right)$ of the cursor on the monitor were calculated as follows:

$$
d^{\prime}=\alpha \times k \times \text { Force }
$$

where $\alpha$ was the amplification coefficient and increased gradually in steps of 0.0059 at each trial, starting from 1 (i.e., no amplification in the first trial) to a maximum of 1.2 at trial 35 , and remained stable until the end of the session (from trial 36 to trial 50). In this way, by applying the same amount of force as in the baseline, the subjects of the experimental group could see the cursor reaching higher lines of the target zone than before and therefore believed to be stronger because of the treatment. Amplification was programmed gradually to prevent that subjects became aware about the manipulation.

Before starting the final session, TENS was applied again together with verbal suggestion of better motor performance. Subjects then repeated the motor task (50 trials), but this time without amplification of the cursor's excursion range. 
Hence, the difference between the two experimental groups was related to the presence or absence of a conditioning procedure. As demonstrated in a recent study (Lutz et al., 2012), reward mechanisms triggered by means of positive visual feedbacks can improve motor performance. By testing these two experimental groups, we could disentangle the effects of placebo-induced expectation from the effects of a potentially rewarding positive visual feedback received during the conditioning phase and eventually influencing fatigue and force production (Lutz et al., 2012).

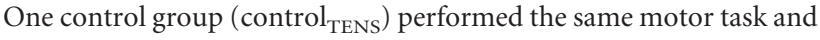
underwent the TENS treatment as described above, but with different verbal information and without amplification of the cursor's displacements. More precisely, these subjects were clearly told that we were conducting a study on the effects of TENS on force production and that they have been assigned to a control group in which the frequency of TENS was completely inefficient in affecting force. This group performed the motor task in the same way as in the baseline (i.e., without any amplification of the cursor's excursion range).

Finally, to control the effects of mere repetition of the motor task on force production, an additional control group (control ${ }_{\text {noTENS }}$ ) was recruited who performed the same motor task in the same sequential sessions as the other groups, but without TENS.

To summarize, we recruited four groups: (1) an experimental group with TENS application, verbal suggestion of force increase, and visual manipulation of the cursor's excursion range ( $\left.\exp _{\text {verbal }+ \text { conditioning }}\right) ;(2)$ an experimental group with TENS application and verbal suggestion of force increase, without visual conditioning ( $\left.\exp _{\text {verbal }}\right)$; (3) a control group with TENS application but without verbal suggestion of force increase and without manipulation ( $\left.\operatorname{control}_{\mathrm{TENS}}\right)$; and (4) a control group without TENS application ( control $_{\text {noTENS }}$ ).

Our interest was to compare the performance of all the groups at the baseline and final sessions. If the induced placebo effect takes place and makes the subjects of the experimental groups expecting to perform better because of the TENS, their expectation and belief about TENS should influence their real outcome, thus inducing higher force levels in the final compared with the baseline session (despite the task being completely identical in the two sessions).

Behavioral data. To evaluate force, we computed two parameters. The mean value of the peak force amplitude obtained from the 50 trials of each session $\left(\right.$ Force $_{\text {peak }}$ ) was normalized to the maximum force expressed during the initial calibration procedure (MVF). This index was defined with the following formula:

$$
\text { Normalized Force }_{\text {peak }}=\frac{\text { Force }_{\text {peak }}}{M V F} \times 100
$$

This index gives information on whether the mean force level achieved by the subjects in the different experimental sessions changed in relation to the maximum voluntary force.

Furthermore, the percentage of strong pressures (Strong ${ }_{\text {press }}$ ) in each session was defined with the following formula:

$$
\text { Strong }_{\text {press }}=\frac{N_{\text {Strong trials }}}{N_{\text {tot trials }}} \times 100
$$

where $N_{\text {tot trials }}$ is the total number of trials in each session (i.e., 50) and $N_{\text {strong trials }}$ is the number of trials in which the peak force amplitude was above the mean value computed in the baseline. In this way, whereas the first parameter (normalized Force peak $_{\text {) }}$ ) is a measure of the subject's mean force level achieved in each session in relation to the MVF, the second parameter (Strong press ) allowed to compute how many times the subject pressed the piston above a certain value, thus giving a measure of the consistency of behavior.

Subjective data. In addition to these objective indices of performance, we also monitored the following subjective variables: (1) Expectation level. We evaluated subjects' expectation about the effects of the TENS in influencing future force production. In particular, after TENS application, we asked subjects to judge how much and in which direction they expected that their subsequent performance would change with respect to the first task execution performed at baseline. To this aim, we admin- istered a 7 points number rating scale (NRS), ranging from -3 ("I expect that my performance will be much worse than at baseline") to 0 ("I expect that my performance will remain the same as in the baseline") to 3 ("I expect that my performance will be much better than at baseline"). This scale was applied after the two TENS applications. Crucial for our interest is the expectation score given by the experimental group after the second TENS application, before executing the final session. The scale was administered to the two experimental groups and also to the subjects of the control group, to check for any potential expectation of performance change, despite the fact that the latter were clearly told that TENS was not effective. (2) Judgment of TENS efficacy. After the execution of the motor task, we asked subjects to report whether TENS had been effective or not in potentiating force production, by means of a $10-\mathrm{cm}$-long visual analog scale (VAS), ranging from 0 ("TENS was not effective at all") to 10 ("TENS was extremely effective"). Again, this scale was applied also to the control group. By means of this scale, we aimed at having an explicit report from the subjects of the experimental group about their belief on the effects of the treatment. (3) Perception offorce. Soon after completion of the motor task in the baseline session, we administered a $10-\mathrm{cm}-\mathrm{long}$ VAS scale on which subjects were asked to mark how strong they felt during the execution of the task (from $0=$ very weak to $10=$ very strong). Subsequently, in the other two sessions (manipulation and final), we administered two 7 point NRS in which subjects were asked to judge how strong they felt in respect to the baseline session (from $-3=$ much weaker, $0=$ like before, to $3=$ much stronger). (4) Sense of effort. After the execution of the motor task, we evaluated the subjective sense of effort in each session, by means of the Borg scale (Borg, 1970), ranging from 6 (rest) to 20 (maximal effort).

In regards to all the subjective indices, as well as to the behavioral parameters, it was crucial to compare the data obtained from all the groups in the baseline and final sessions (i.e., before and after the experimental procedure).

TMS task. When investigating top-down, cognitive modulations on the corticospinal system, it is of fundamental importance to exclude all the possible bottom-up confounding factors that could influence excitability, such as the actual force level (Rösler et al., 2002; Säisänen et al., 2008), joint velocity (Duclay et al., 2011), and background EMG activity (Devanne et al., 1997; Hasegawa et al., 2001). Because in our study it was predicted that the placebo manipulation induced higher force levels in the experimental groups than in the control groups, we had to rule out this confounding factor in the neurophysiological investigation. To this purpose, we introduced an additional task, called TMS task, that was performed by all the subjects soon after the main motor task. In this task, in addition to the lines of the target zone, a red line appeared on the PC monitor. The red line represented the $30 \%$ of the MVF measured during the initial calibration procedure (Fig. $1 D$ ). The subjects were asked to control the pressure of the piston to keep the cursor on the red line. When the cursor was located on the red line, its color turned from yellow to green $(30 \pm 1 \% \mathrm{MVF})$. This visual feedback allowed the subjects to maintain the correct pressure. If the cursor remained stable on the red line for at least $500 \mathrm{~ms}$, the software automatically triggered the TMS pulse, which was delivered in correspondence to the FDI optimal scalp position at $100 \%$ of the resting motor threshold (rMT). The TMS task consisted of 16 trials (for a total of 16 TMS pulses), and each trial lasted $5000 \mathrm{~ms}$ to give the subjects enough time to stabilize the cursor on the red line before the TMS pulse could be triggered. The pulse could occur randomly in a time window between 500 and $1300 \mathrm{~ms}$ after the cursor had turned green (Fig. 1D). In this way, the TMS pulse was always delivered when the position of the finger was stable and the pressure was at the $30 \%$ of MVF to avoid MEP saturation (Kischka et al., 1993; Taylor et al., 1997). In each trial, EMG recording began $100 \mathrm{~ms}$ before and finished $1000 \mathrm{~ms}$ after the TMS pulse. After each TMS pulse, a $10 \mathrm{~s}$ interval was inserted before starting the next trial (Fig. 1D).

TMS stimulation and EMG recording. Surface EMG recordings were obtained from the motor point of the FDI and abductor digiti minimi $(\mathrm{ADM})$ muscles of the right hand with bipolar self-adhesive $\mathrm{Ag}-\mathrm{AgCl}$ electrodes $(1.5 \times 2.5 \mathrm{~cm})$ in a belly-tendon montage. The ground electrode was attached to the wrist. EMG signals were bandpass filtered (20 $\mathrm{Hz}$ to $2.5 \mathrm{kHz}$; plus $50 \mathrm{~Hz}$ notch) (D360, Digitimer), amplified at a gain 
of 1000 (Digitimer), digitized at $5 \mathrm{kHz}$ with laboratory interface (Cambridge Electronic Design 1401) controlled by Spike 2 (version 6, Cambridge Electronic Design) and analyzed off-line.

Single-pulse TMS was applied through a figure-of-eight coil (outer diameter of each wing $110 \mathrm{~mm}$ ) connected to a STM 9000 magnetic stimulator (Ates-EBNeuro) producing a maximum output of $2 \mathrm{~T}$ at the coil surface. The current waveform was biphasic, and the coil was placed tangentially to the skull at an angle of $45^{\circ}$ to the sagittal plane. This coil orientation induces posterior to anterior current flowing in the cortical tissue in a plane approximately perpendicular to central sulcus and allows stimulation at the lowest motor threshold (Brasil-Neto et al., 1992; Mills et al., 1992). To minimize unwanted motion during the experiment, the coil was held by an articulated arm, and the head of the subject was supported by a U-shape holder. The optimal scalp position was detected by moving the intersection of the coil around the motor hand area of the left motor cortex (M1) and by delivering TMS pulses with constant intensity until stable and maximal MEPs could be evoked in the relaxed FDI. The rMT was defined as the lowest stimulus intensity able to evoke MEPs with an amplitude of at least $50 \mu \mathrm{V}$ in at least five often trials in the FDI muscle.

In addition to MEP amplitude recorded from the two muscles (FDI ${ }_{\mathrm{amp}}$ and $\mathrm{ADM}_{\text {amp }}$ ), we also measured the duration of the CSP. The CSP is a period of silence in the EMG following the MEP and occurs only when the TMS pulse is delivered on an active muscle. In our case, the CSP could be recorded from the FDI (FDI csp ). The duration of the CSP was measured between two extremes: the beginning of the CSP was defined by the onset of the TMS pulse and the end of the CSP was defined by the moment in which the rectified EMG activity, averaged over a $10 \mathrm{~ms}$ period, had returned to $50 \%$ of prestimulus values (Butler et al., 2012).

TMS at rest. MEP amplitude from the FDI and ADM was also measured with subjects at rest ( $\mathrm{FDI}_{\text {amp_rest }}$ and $\left.\mathrm{ADM}_{\text {amp_rest }}\right)$, by stimulating at $120 \%$ rMT before starting the protocol (10 trials) and after finishing it (10 trials). MEP amplitudes at rest allowed to check whether the changes in corticospinal excitability were task-specific or more general.

Additional investigation: input/output (I/O) curve. To thoroughly investigate eventual changes of corticospinal excitability at rest after a placebo procedure, we measured the I/O curve from the FDI and ADM muscles in the $\exp _{\text {verbal }}$ group. After having defined the stimulus intensity (SI) needed to evoke MEPs of $\sim 1 \mathrm{mV}$ (Rosenkranz et al., 2007), the I/O curve was obtained by delivering single TMS pulses at different intensities: Ten TMS pulses were delivered with a blocked design at 70\%, $80 \%$, $90 \%, 100 \%, 110 \%, 120 \%, 130 \%$, and $140 \%$ of SI. For each subject, we computed the mean MEP amplitude (peak-to-peak) at each stimulus intensity, and then we computed the steepness (slope) of the linear regression line through the data points between $90 \%$ and $130 \%$ SI (Rosenkranz et al., 2007). This procedure was performed with subjects at rest before and after the whole experimental protocol.

Data handling. Before calculating the mean value of Force peak $_{\text {in each }}$ session and subject, behavioral data were cleaned in two ways: (1) trials in which participants did not press the piston after having pressed the mouse key were removed $\left(0.27 \%\right.$ for $\exp _{\text {verbal }+ \text { conditioning }}$ group, $0.48 \%$ for $\exp _{\text {verbal }}$ group, $0.53 \%$ for control TENS $_{\text {group, and } 0.53 \% \text { for }}$ control $_{\text {noTENS }}$ group); and (2) afterward, data of each subject in each session were inspected to exclude potential outliers (i.e., values $2 \mathrm{SD}$ above or below the mean value). By doing this, no outliers were found. These procedures were not necessary for the TMS task because, in this case, if the subject missed a trial (i.e., he/she was not able to maintain the cursor on the red line), the TMS pulse was not delivered and the trial was repeated again. Hence, in this case, the task was repeated until 16 TMS pulses were delivered and, consequently, there were no missed trials. Moreover, because the subjects performed the task always at a certain amount of force (i.e., $30 \%$ MVF), there were no outliers.

The neurophysiological data recorded during the TMS task were screened as follows: Prestimulation EMG level was assessed by calculating the root mean square of the background EMG (EMG background rms $\left._{\text {ras }}\right)$ $>50 \mathrm{~ms}$ before MEP onset. Trials for which the FDI MEP amplitude was lower than the mean $\mathrm{EMG}_{\text {background_rms }}$ were discarded (Alaerts et al., 2010). Furthermore, data of all the measured neurophysiological parameters (i.e., $\mathrm{FDI}_{\mathrm{amp}}, \mathrm{ADM}_{\mathrm{amp}}, \mathrm{FDI}_{\mathrm{csp}}$, FDI EMG $\mathrm{EMackground}_{\text {_rms }}$, and ADM
$E M G_{\text {background_rms }}$ ) were inspected to exclude outliers (i.e., values $2 \mathrm{SD}$ above or below the mean value for each subject in each session). After these procedures, a total of $6.76 \%$ trials were removed $(6.94 \%$ for

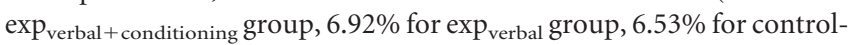
TENS group, and $6.81 \%$ for control $\mathrm{n}_{\text {noTENS }}$ group).

In regards to the neurophysiological data recorded at rest (before starting the protocol and after finishing it), we proceeded as follows: First, we removed all the trials in which $\mathrm{EMG}_{\text {background_rms }}$ of the FDI and ADM muscles was $>10 \mu \mathrm{V}$ because evidence suggests that, for resting muscles, $\mathrm{EMG}_{\text {background_rms }}$ should be $<10 \mu \mathrm{V}$ (Coxon et al., 2006). Furthermore, data of all the measured neurophysiological parameters (i.e., FDI $_{\text {amp_rest }}$, $\mathrm{ADM}_{\text {amp_rest }}$, FDI EMG $\mathrm{G}_{\text {background_rms, }}$, and $\mathrm{ADM}$ EMG $\mathrm{G}_{\text {background_rms }}$ ) were inspected to exclude outliers (i.e., values 2 SD above or below the mean value for each subject in each session). After these procedures, a total of $3.72 \%$ trials were discarded $\left(2.50 \%\right.$ for $\exp _{\text {verbal }+ \text { conditioning }}$ group, $5 \%$ for $\exp _{\text {verbal }}$ group, $6.33 \%$ for control $_{\text {TENS }}$ group, and $2.14 \%$ for control noTENS $_{\text {group). }}$

In addition to the computations described above, we also computed the difference of normalized Force peak $_{\text {and Strong }}$, between the final and baseline sessions (final - baseline). This index (called change) is informative of the amount of change in performance before and after the procedure between all the groups. This index was applied also to the subjective feeling of force, the sense of effort, MEP amplitude, and CSP duration.

Statistical analysis. Analyses were performed using SPSS Statistics 19 software (SPSS). Repeated-measures analyses of variance (rmANOVAs) were used to assess the effects of group (between-subject factor, 4 levels: $\exp _{\text {verbal }+ \text { conditioning, }}, \exp _{\text {verbal }}$, control ${ }_{\text {TENS }}$, control noTENS $_{\text {nd sessions }}$ (within-subject factor, 2 levels: baseline vs final) in regards to the behavioral parameters (normalized Force ${ }_{\text {peak }}$, Strong ${ }_{\text {press }}$ ), subjective parameters (perception of force and sense of effort), and neurophysiological parameters $\left(\mathrm{FDI}_{\mathrm{amp}}, \mathrm{ADM}_{\mathrm{amp}}, \mathrm{FDI} \mathrm{csp}_{\mathrm{csp}}, \mathrm{FDI}\right.$ and $\mathrm{ADM} \mathrm{EMG}_{\text {background_rms }}$ $\left.\mathrm{FDI}_{\text {amp_rest }}, \mathrm{ADM}_{\text {amp_rest }}\right)$. One-way ANOVA was used to compare across groups the level of expectation (NRS scores), the judgments about the effects of TENS (VAS scores), the change index for the different variables, and the performance during the manipulation session.

With regard to the additional neurophysiological investigation, MEP amplitudes of the I/O curves recorded from the FDI and ADM muscles at different intensities of stimulation in the baseline and final sessions were analyzed by means of rmANOVA with session (baseline vs final) and intensity of stimulation $(70 \%, 80 \%, 90 \%, 100 \%, 110 \%, 120 \%, 130 \%$, $140 \%)$ as within-subjects factors. Moreover, the slope values of the I/O curves were compared before and after the experimental procedure by means of paired samples $t$ tests.

In all the analyses, post hoc comparisons were made by means of $t$ tests for paired or independent samples, applying the Bonferroni correction for multiple comparisons where necessary. The level of significance was set at $p<0.05$. Data are mean \pm SE.

\section{Results}

Levene's test revealed homogeneous variances of the behavioral, subjective, and neurophysiological data $(p>0.084$, for all the variables). MVF as measured in the initial calibration phase did not differ between the four groups ( $\exp _{\text {verbal }+ \text { conditioning }}, 19.93 \pm$ $0.79 \mathrm{~N}$; $\exp _{\text {verbal }}, 19.5 \pm 0.46 \mathrm{~N}$; control ${ }_{\text {TENS }}, 19.7 \pm 0.73 \mathrm{~N}$; control $_{\text {noTENS }}, 21.14 \pm 0.62 \mathrm{~N}$; one-way ANOVA, $F_{(3,56)}=1.2, p=$ $0.319)$.

\section{Behavioral data}

ANOVA on normalized Force $_{\text {peak }}$ revealed a significant session $X$ group interaction $\left(F_{(3,56)}=6.64, p=0.001\right)$, no effect of session $\left(F_{(1,56)}=0.8, p=0.376\right)$, and no effect of group $\left(F_{(3,56)}=2.51\right.$, $p=0.068)$. Post hoc comparisons showed that the $\exp _{\mathrm{verbal}+\text { conditioning }}$ group was significantly stronger in the final $(103 \pm 0.4 \%)$ compared with the baseline $(97 \pm 0.31 \%)$ session $(p=0.031)$ (Fig. $2 A, B)$. Higher force values in the final (102 $\pm 0.38 \%)$ compared with the baseline session $(97 \pm 0.25 \%)$ were observed also in the 


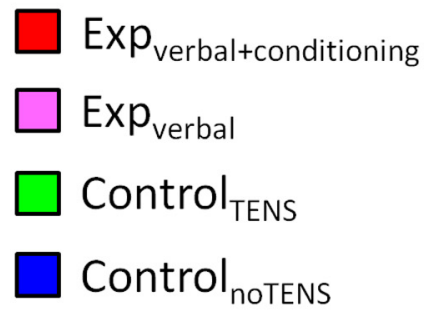

B
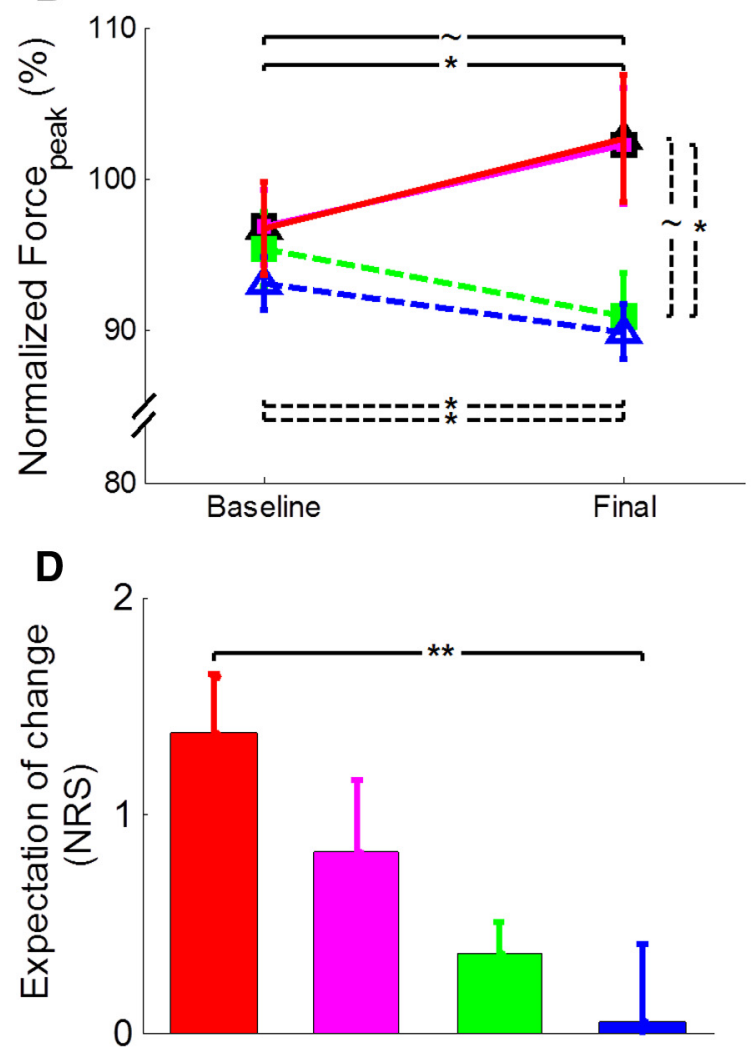

$\mathbf{F}$

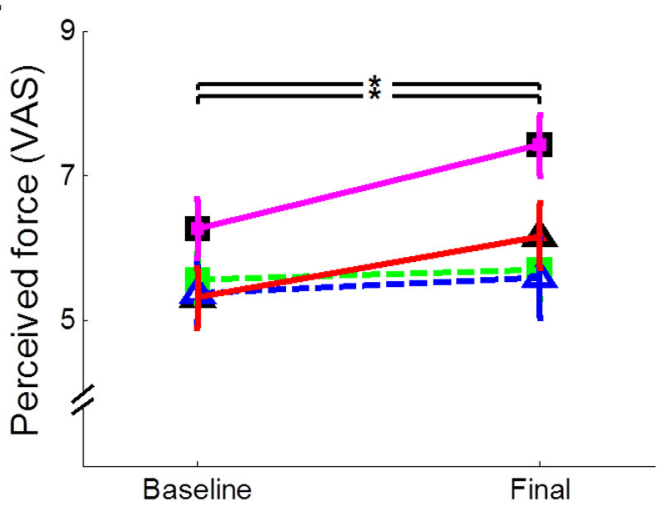

A

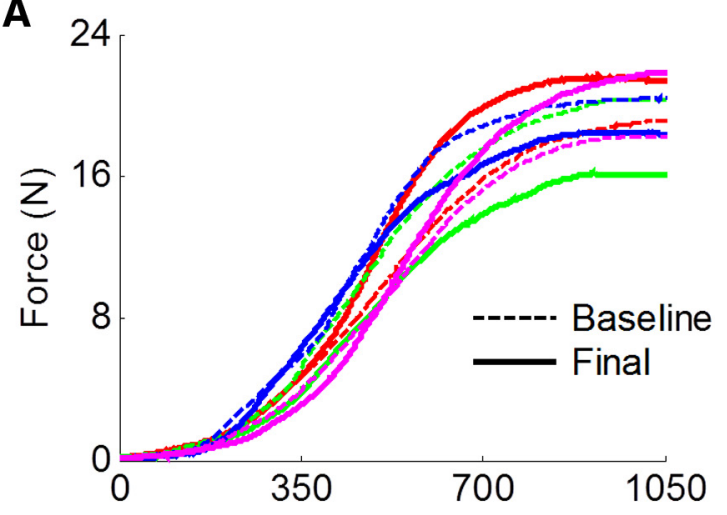

C

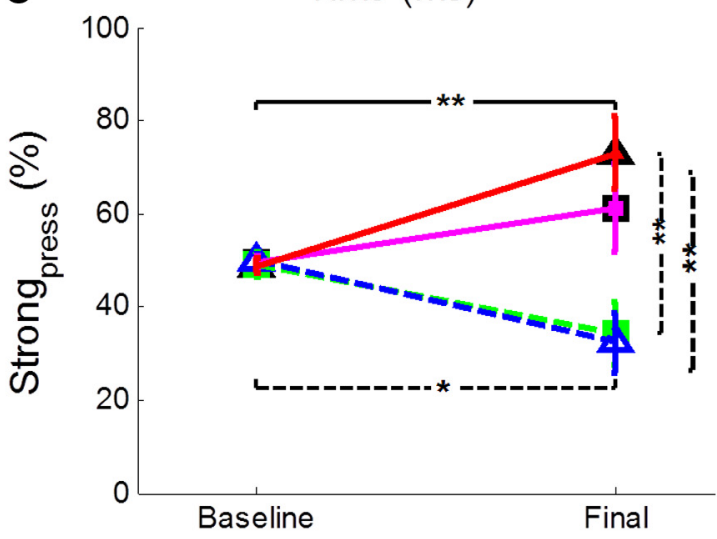

E

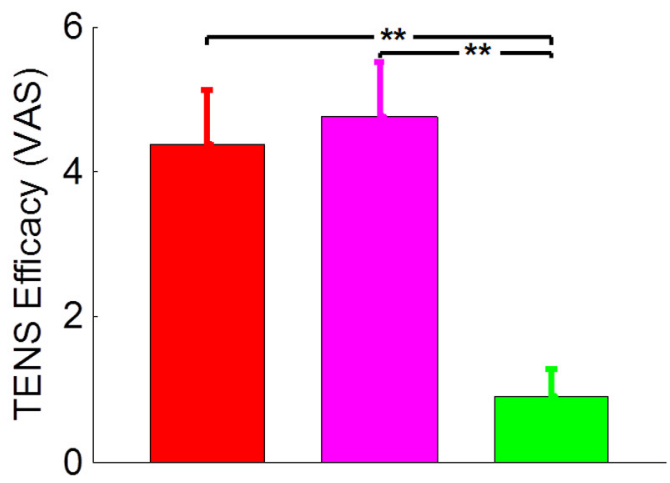

G

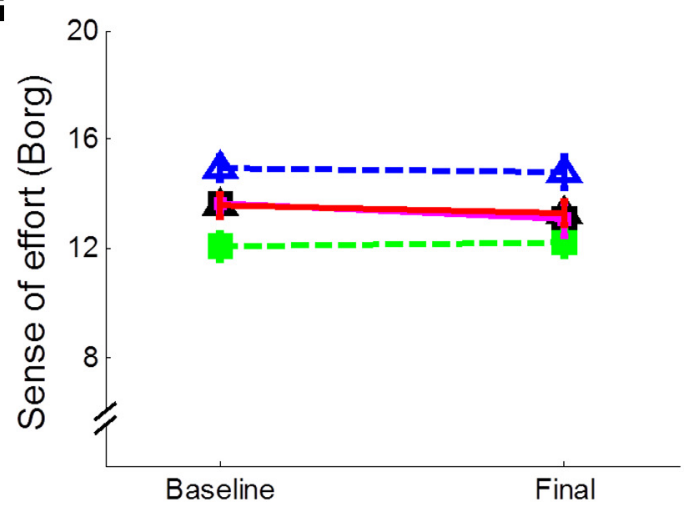

Figure 2. Illustration of the behavioral and subjective data. $A$, Force profile obtained from the average of the 50 trials of the baseline (dashed lines) and final (continuous lines) sessions in one subject of the $\exp _{\text {verbal + conditioning }}$ group (red lines), one subject of the $\exp _{\text {verbal }}$ group (magenta lines), one subject of the control TENS $_{\text {group (green lines), and one subject of the control }}$ notens $g$ group

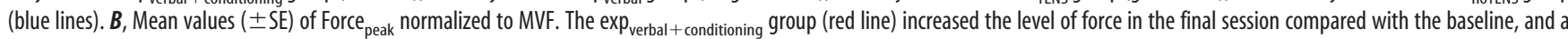
tendency was observed in the $\exp _{\text {verbal }}$ group, whereas the control ${ }_{\text {TENS }}$ and control $\left.\right|_{\text {nTtens }}$ groups (green and blue lines) showed an opposite pattern, with a reduction of force. $C$, Percentage ( \pm SE) of strong pressures. The $\exp _{\text {verbal+conditioning }}$ group pressed the piston more often with strong pressures in the final session compared with the baseline, (Figure legend continues.) 
$\exp _{\text {verbal }}$ group, although with a tendency $(p=0.058)$. Conversely, the two control groups were significantly weaker in the final (control $_{\text {TENS }}, 91 \pm 0.29 \%$; control $_{\text {noTENS }}, 90 \pm 0.18 \%$ ) compared with the baseline (control ${ }_{\mathrm{TENS}}, 95 \pm 0.24 \%$; $_{\text {control }}$ noTENS, $93 \pm$ $0.18 \%$ ) session (for both comparisons, $p<0.043$ ). Moreover, a significant difference was found in the final session between the $\exp _{\text {verbal }+ \text { conditioning }}$ and the control noTENs $_{\text {group }}(p=0.044)$, and a tendency toward significance was found also between the ex$p_{\text {verbal }}$ and the control ${ }_{\text {noTENs }}$ group $(p=0.059)$. Analysis of change confirmed a significant effect of group $\left(F_{(3,56)}=6.64, p=\right.$ 0.001). Post hoc comparisons showed significant differences between the $\exp _{\mathrm{verbal}+\text { conditioning }}$ group and the two control groups (for both comparisons, $p<0.022$ ). Moreover, a difference was found between the $\exp _{\text {verbal }}$ group and the two control groups $(p<0.035)$. Hence, these findings hint at an increase of normalized Force $_{\text {peak }}$ in the experimental groups and a decrease in the two control groups.

ANOVA on Strong ${ }_{\text {press }}$ disclosed a significant effect of group $\left(F_{(3,56)}=4.94, p=0.004\right)$ because of higher values in the

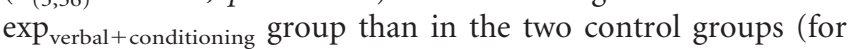
both comparisons, $p<0.014)$ and no effect of session $\left(F_{(1,56)}=\right.$ $0.07, p=0.797)$. The interaction session $\times$ group was also significant $\left(F_{(3,56)}=7.74, p<0.001\right)$. Post hoc comparisons showed that the $\exp _{\text {verbal }}+$ conditioning group pressed the piston more frequently stronger in the final $(73.03 \pm 7.84 \%)$ compared with the baseline $(48.74 \pm 1.6 \%)$ session $(p=0.007)$ (Fig. $2 C)$. Conversely, the two control groups were more frequently weaker in the final (control TENS $_{1}, 34.40 \pm 6.8 \%$; control $_{\text {noTENS }}, 32.36 \pm$ $6.54 \%$ ) compared with the baseline ( control $_{\text {TENS }}, 49.20 \pm 2.7 \%$; control $_{\text {noTENS }}, 50.03 \pm 1.41 \%$ ) session (for both comparisons, $p<0.025)$. Moreover, in the final session, the $\exp _{\text {verbal }+ \text { conditioning }}$ group had significantly higher values than $\operatorname{control}_{\text {TENS }}(p=$ $0.005)$ and control noTENS $(p=0.003)$. Analysis of change showed a significant effect of group $\left(F_{(3,56)}=7.74, p<0.001\right)$. Post hoc comparisons showed significant differences between the $\exp _{\text {verbal }+ \text { conditioning group and the two control groups (for both }}$ comparisons, $p<0.003$ ). Moreover, a difference was found between the $\exp _{\text {verbal }}$ group and the control ${ }_{\text {noTENs }}$ group $(p=$ $0.037)$. These findings support the notion that the proposed procedure was successful in inducing enhancement of force production that was more pronounced in the experimental group subjected to the conditioning procedure.

One-way ANOVA of performance during the manipulation session revealed no significant difference between the four groups either in normalized Force $e_{\text {peak }}\left(F_{(3,56)}=1.09, p=0.360\right)$ or in

(Figure legend continued.) whereas the two control groups showed the opposite pattern. A significant difference between groups was found in the final session. $D$, Mean scores ( $\pm S E$ ) given at the expectation scale. The question related to this scale was as follows: "Do you expect that your performance will change compared with the very first session? If yes, how?" Subjects could answer on a 7 point NRS, in which positive scores indicate that they expected a benefit in force production after TENS. The $\exp _{\text {verbal }+ \text { conditioning }}$ group and the $\exp _{\text {verbal }}$ group expected a positive change of performance before starting the final session. $\boldsymbol{E}$, Mean scores $( \pm S E$ ) related to the efficacy of the treatment. The question related to this scale was as follows: "Was the treatment really effective in changing your performance? If yes, how much?" Subjects could answer this question on a VAS scale. Scores are reported only for the groups in which TENS was applied. As shown in the figure, the two experimental groups reported that the treatment was more effective compared with the control ${ }_{\text {TENS }}$ group. $\boldsymbol{F}$, Mean ( $\pm S E$ ) subjective perception of force. Perception of force was higher in the final compared with the baseline session in the two experimental groups. G, Mean scores of the sense of effort (given on the Borg scale; Borg, 1970). The four groups did not change the perception of effort from baseline to final session. ${ }^{* *} p<$ 0.01. ${ }^{*} p<0.05$. $\sim p<0.059$.
Strong $_{\text {press }}\left(F_{(3,56)}=0.869, p=0.463\right)$, thus ruling out lower levels of fatigue in the experimental groups.

\section{Subjective data}

Analysis of the expectation level showed a significant effect of group $\left(F_{(3,56)}=4.35, p=0.008\right)$ because of higher values in the $\exp _{\text {verbal }+ \text { conditioning }}(1.38 \pm 0.25)$ compared with the control noTENS $_{\text {n }}$ group $(0.05 \pm 0.36)$ (Fig. $2 D)$.

The analysis of the judgments on the effects of TENS revealed significantly higher scores in the $\exp _{\mathrm{verbal}+\text { conditioning }}(4.36 \pm$ $0.77)$ and in the $\exp _{\text {verbal }}(4.76 \pm 0.74)$ groups compared with the control $_{\text {TENS }}$ group $(0.91 \pm 0.37)\left(F_{(2,42)}=10.52, p<0.001\right)$ (Fig. $2 E)$. This finding confirms that both the experimental groups (with and without conditioning) thought that the treatment was effective after completing the final motor task.

Analysis of force perception disclosed a significant effect of the factor session $\left(F_{(1,56)}=19.43, p<0.001\right)$ because of overall higher values in the final $(6.22 \pm 0.23)$ compared with the baseline session $(5.64 \pm 0.2)$. The session $\times$ group interaction was also significant $\left(F_{(3,56)}=3.53, p=0.021\right)$. Post hoc comparisons showed that, in the two experimental groups, subjective feelings of force were higher in the final ( $\exp _{\text {verbal+conditioning }}, 6.15 \pm$ 0.44 ; $\left.\exp _{\text {verbal }}, 7.4 \pm 0.41\right)$ than in the baseline session $\left(\exp _{\text {verbal }+ \text { conditioning, }} 5.32 \pm 0.42 ; \exp _{\text {verbal }}, 6.3 \pm 0.41\right)$ (for both comparisons, $p<0.008$ ) (Fig. $2 F$ ). Analysis of change in force perception disclosed a significant effect of group $\left(F_{(3,56)}=3.54\right.$, $p=0.020)$ because of different values between the $\exp _{\text {verbal }}$ group and the control ${ }_{\text {TENS }}$ group $(p=0.053)$.

Analysis of the sense of effort revealed a significant effect of group $\left(F_{(3,56)}=6.39, p=0.001\right)$ because of higher values in the control $_{\text {noTENS }}$ group $(14.87 \pm 0.44)$ compared with the control ${ }_{\text {TENS }}$ group $(12.13 \pm 0.44)$, whereas session $\left(F_{(1,56)}=1.45, p=0.234\right)$ and session $\times$ group $\left(F_{(3,56)}=0.64, p=0.592\right)$ were not significant (Fig. $2 G$ ). Analysis of change in the sense of effort disclosed no significant effect of group $\left(F_{(3,56)}=1.44, p=0.592\right)$.

\section{Neurophysiological data}

One-way ANOVA on the rMT of the four groups revealed no significant differences $\left(F_{(3,56)}=1.01, p=0.394\right)$.

ANOVA on the FDI ${ }_{\mathrm{amp}}$ revealed no effect of session $\left(F_{(1,56)}=\right.$ $0.57, p=0.454)$ and no effect of group $\left(F_{(3,56)}=0.89, p=0.451\right)$, but a significant session $\times$ group interaction $\left(F_{(3,56)}=6.47, p=\right.$ 0.001). Post hoc comparisons disclosed that the two experimental

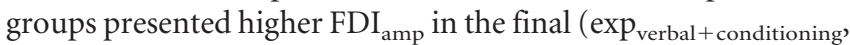
$2.75 \pm 0.32 \mathrm{mV}$; $\exp _{\text {verbal }}, 2.89 \pm 0.25 \mathrm{mV}$ ) than in the baseline $\left(\exp _{\text {verbal+conditioning }}, 2.33 \pm 0.31 \mathrm{mV} ; \exp _{\text {verbal }}, 2.59 \pm 0.22 \mathrm{mV}\right)$ session (for both comparisons, $p<0.027$ ) (Fig. 3A). Conversely,

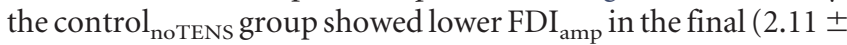
$0.22 \mathrm{mV})$ than in the baseline $(2.45 \pm 0.2 \mathrm{mV})$ session $(p=$ $0.027)$. One-way ANOVA on the change confirmed a significant effect of group $\left(F_{(3,56)}=6.47, p=0.001\right)$. Post hoc comparisons revealed significant differences between the $\exp _{\text {verbal+conditioning }}$ group and both control groups $(p<0.034)$ and between the $\exp _{\text {verbal }}$ and control $l_{\text {noTENs }}$ group $(p=0.015)$. These findings hint at a different level of corticospinal excitability in the four groups of participants.

ANOVA on the $\mathrm{ADM}_{\mathrm{amp}}$ revealed no effect of session $\left(F_{(1,56)}\right.$ $=1.12, p=0.294)$, no effect of group $\left(F_{(3,56)}=0.198, p=0.898\right)$, and no session $\times$ group interaction $\left(F_{(3,56)}=1.71, p=0.176\right)$ (Fig. $3 B$ ), suggesting that the different corticospinal modulation between the groups is specific for the FDI muscle.

Analysis of the $\mathrm{FDI}_{\mathrm{csp}}$ revealed no effect of session $\left(F_{(1,56)}=\right.$ $0.158, p=0.692)$ and no effect of group $\left(F_{(3,56)}=0.926, p=0.434\right)$, 

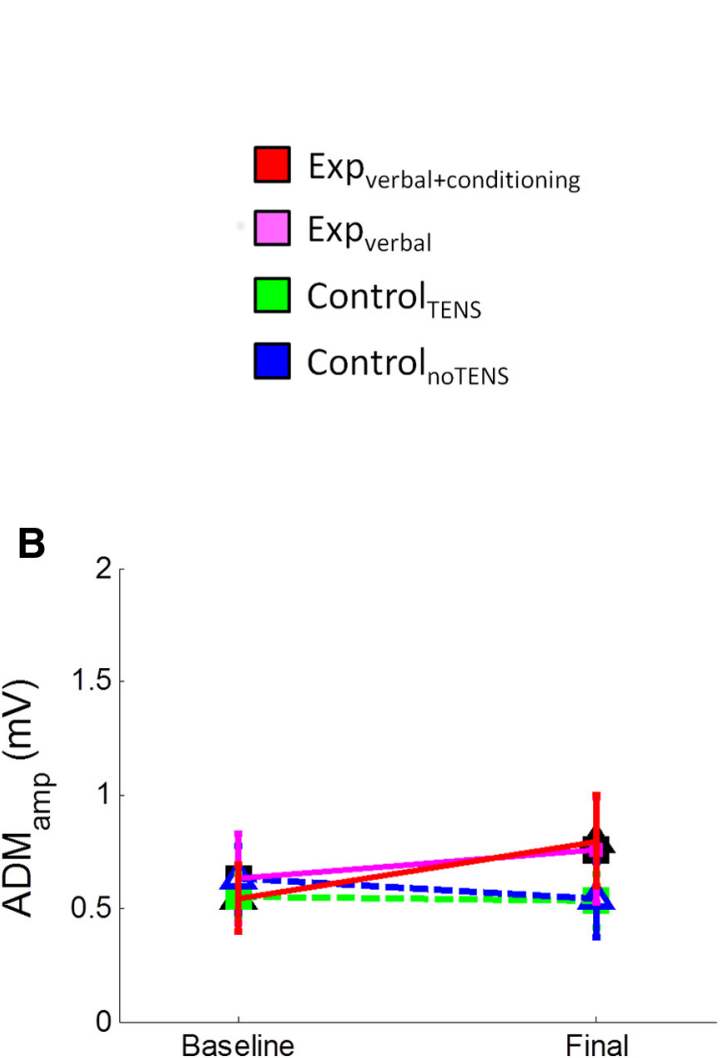
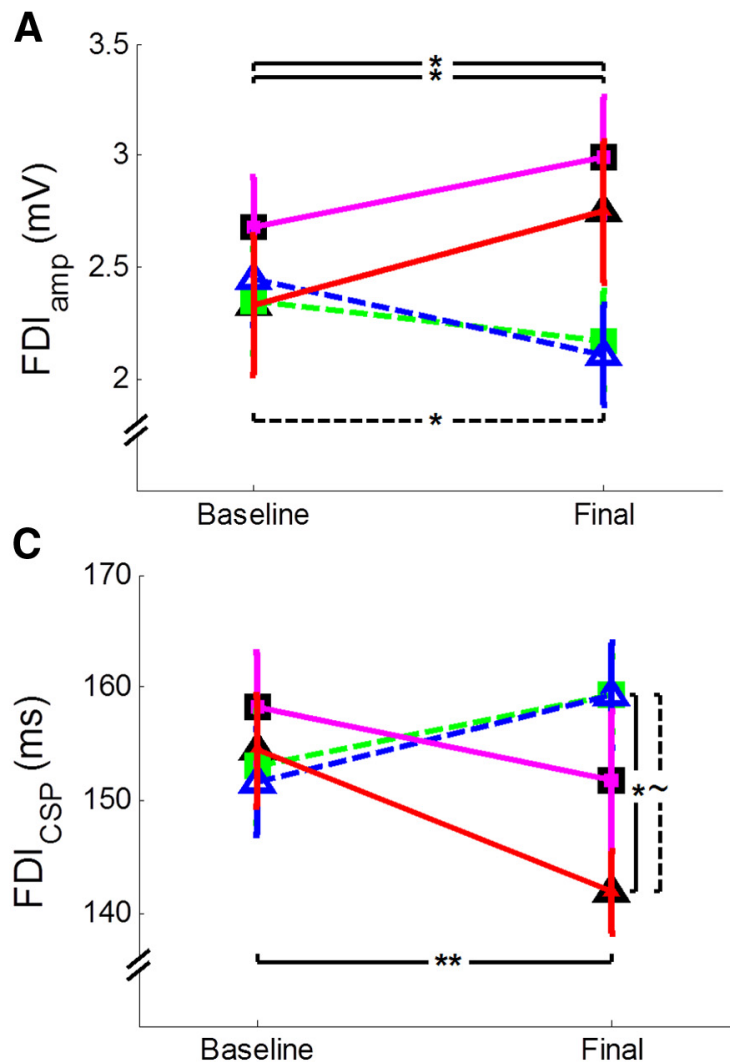

Figure 3. Illustration of the mean ( \pm SE) neurophysiological data obtained from the four groups of participants at the TMS task in the baseline and final sessions. $\boldsymbol{A}$, Mean MEP amplitude (in

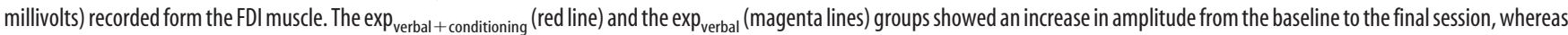
the control $\left.\right|_{\text {notens }}$ group showed a decrease. $\boldsymbol{B}$, Mean MEP amplitude recorded from the ADM muscle. No difference has been found between the groups and the sessions, suggesting that the effect

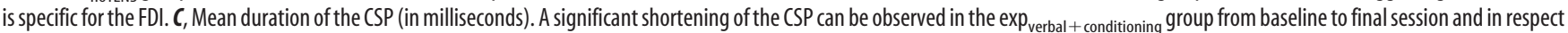
to the two control groups in the final session. ${ }^{* *} p<0.001 .{ }^{*} p<0.05 . \sim p<0.059$.

but a significant session $\times$ group interaction $\left(F_{(3,56)}=4.07, p=\right.$ 0.011). Post hoc comparisons showed that the $\exp _{\text {verbal }+ \text { conditioning }}$ group presented shorter $\mathrm{FDI}_{\mathrm{csp}}$ duration in the final (141.9 \pm $3.66 \mathrm{~ms})$ than in the baseline $(154.4 \pm 4.94 \mathrm{~ms})$ session $(p=$ 0.009) (Fig. 3C). Moreover, in the final session, the FDI ${ }_{\text {csp }}$ dura-

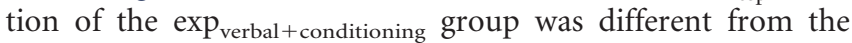
control $_{\text {TENS }}$ group $(p=0.038)$ and with a tendency to the control $_{\text {noTENs }}$ group $(p=0.059)$. One-way ANOVA on the change confirmed a significant effect of group $\left(F_{(3,56)}=4.07, p=0.011\right)$, and post hoc comparisons showed significant differences between the $\exp _{\text {verbal+conditioning }}$ group and both control groups $(p<$ $0.041)$. These findings suggest that the inhibitory circuits are significantly modulated after a placebo procedure consisting of verbal suggestion and conditioning. Representative MEPs of one subject for each group are illustrated in Figure 4.

To rule out whether the enhanced MEP amplitude was a mere reflection of higher force levels achieved by the experimental groups than by the two control groups, we analyzed (rmANOVA) the level of the force of each group ( $\exp _{\text {verbal + conditioning, }} \exp _{\text {verbal }}$,

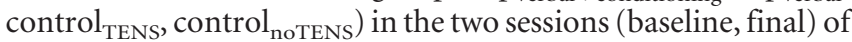
the TMS task (i.e., in the moment in which the TMS pulse was applied). This analysis showed no effect of group $\left(F_{(3,56)}=0.951\right.$, $p=0.422)$, no effect of session $\left(F_{(1,56)}=0.22, p=0.641\right)$, and no session $\times$ group interaction $\left(F_{(3,56)}=1.45, p=0.233\right)$, suggesting that, during the TMS task, the force level was the same in all the groups and in both sessions (Fig. 5A). More precisely, participants pressed the piston with the same amount of force (i.e., at $\sim 30 \%$ of the initially measured MVF) both in the baseline
( $\exp _{\text {verbal }+ \text { conditioning }}$ group, $6.82 \pm 0.22 \mathrm{~N}$; $\exp _{\text {verbal }}$ group, $6.79 \pm 0.19 \mathrm{~N}$; control $_{\text {TENS }}$ group, $6.85 \pm 0.24 \mathrm{~N}$; control $_{\text {noTENS }}$ group, $7.32 \pm 0.19 \mathrm{~N}$ ) and in the final session ( $\exp _{\text {verbal+conditioning }}$

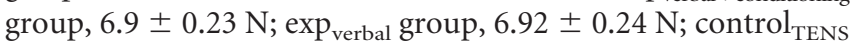
group, $6.84 \pm 0.24 \mathrm{~N}$; control noTeNs $_{\text {group, }} 7.21 \pm 0.18 \mathrm{~N}$ ). This suggests that the MEP amplitude was not influenced by the level of force exerted at the time of the TMS pulse.

To control whether the MEP amplitude was influenced by the different activation in the preceding EMG activity, we analyzed (rmANOVA) the EMG background activity before the MEP onset of the four groups and in the two sessions. ANOVA on the FDI and $\mathrm{ADM} E \mathrm{EMG}_{\text {background_rms }}$ disclosed no effect of group (FDI: $\left.F_{(3,56)}=0.858, p=0.468 ; \mathrm{ADM}: F_{(3,56)}=1.08, p=0.365\right)$, no effect of session (FDI: $F_{(1,56)}=0.135, p=0.715$; ADM: $F_{(1,56)}=$ $0.032, p=0.859)$, and no session $\times$ group interaction (FDI: $F_{(3,56)}=0.482, p=0.696$; $\mathrm{ADM}: F_{(3,56)}=0.595, p=0.621$ ) (Fig. $5 B, C)$. This suggests that the EMG background activity before the MEP onset was similar in all the groups and in both sessions; therefore, the MEP amplitude was not influenced by differences in preceding EMG activity.

Finally, we analyzed the neurophysiological data recorded at rest (i.e., before starting the whole protocol and after its completion).

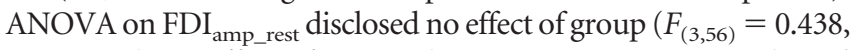
$p=0.726)$, no effect of session $\left(F_{(1,56)}=0.294, p=0.590\right)$, and no session $\times$ group interaction $\left(F_{(3,56)}=0.742, p=0.531\right)$ (Fig. $5 D)$. ANOVA on the $\mathrm{ADM}_{\text {amp rest }}$ revealed no effect of session $\left(F_{(1,56)}=0.712, p=0.402\right)$ and no session $\times$ group interaction $\left(F_{(3,56)}=0.897, p=0.448\right)$, but a significant effect of group 

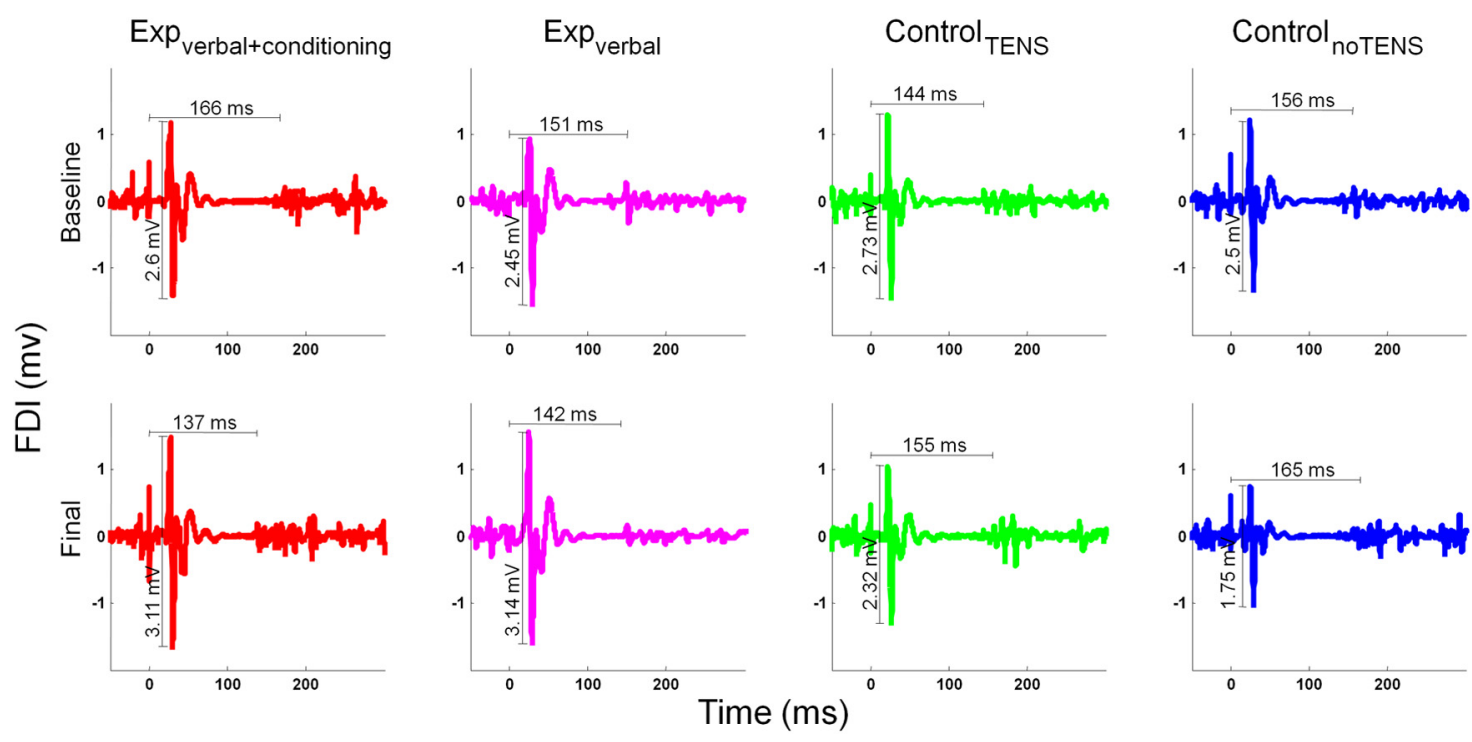

Figure 4. Representative neurophysiological traces recorded from the FDI muscle in one subject of the $\exp _{\text {verbal }+ \text { conditioning }}$ group (red traces), one subject of the exp verbal + conditioning $_{\text {group }}$

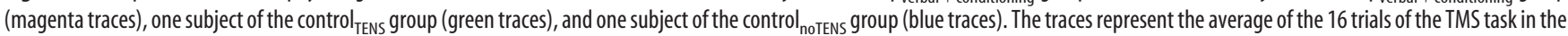
baseline session (top) and in the final session (bottom). TMS pulse was delivered at $0 \mathrm{~ms}$. MEP amplitude is reported in millivolts and CSP duration is shown in milliseconds. As illustrated in the figure, MEP amplitude was higher in the subjects of the experimental groups at the final session compared with baseline, whereas it was lower in the two subjects of the control groups. CSP duration was shorter in the final than in the baseline session in the subject of the $\exp _{\text {verbal }+ \text { conditioning }}$ group.

$\left(F_{(3,56)}=3.04, p=0.036\right)$ because of overall lower MEPs in the $\exp _{\text {verbal }}$ group compared with the $\exp _{\text {verbal }+ \text { conditioning }}$ group $(p=0.032)$ (Fig. $5 E)$. One-way ANOVA on the change did not disclose any significant effect of group, either in the $\mathrm{FDI}_{\text {amp_rest }}$ $\left(F_{(3,56)}=0.742, p=0.531\right)$ or in the $\mathrm{ADM}_{\text {amp_rest }}\left(F_{(3,56)}=0.897\right.$, $p=0.448)$. These findings confirm that the corticospinal excitability at rest did not change across sessions.

\section{Additional investigation- $\mathrm{I} / \mathrm{O}$ curve}

Analysis of the FDI and ADM I/O curves in the $\exp _{\text {verbal }}$ group revealed a significant effect of intensity $\left(F_{(7,98)}>80.74, p<\right.$ 0.001 ) because of progressively greater MEP amplitudes at increasing TMS intensities (for all comparisons, $p<0.026$ ) (Fig. 6). Conversely, the factor session $\left(F_{(1,14)}<1.17, p>0.297\right)$ and the interaction session $X$ intensity $\left(F_{(7,98)}<1.84, p>0.088\right)$ were not significant, suggesting that the distribution of the I/O curves of the FDI and ADM did not change throughout the experimental procedure. Finally, analysis of the slope revealed no significant change between sessions in the FDI $\left(t_{(14)}=1.12, p=0.282\right)$ or in the $\operatorname{ADM}\left(t_{(14)}=1.09, p=0.295\right)$, further hinting at the lack of neurophysiological modulation at rest.

\section{Discussion}

The results of the present study show that force can be increased by inducing expectation and belief about the efficacy of a treatment. More importantly, we highlight, for the first time, the neurophysiological correlates of this effect, by demonstrating a placebo-induced enhancement of corticospinal excitability. As will be outlined below, these findings have important implications in shedding new light on the brain-body interaction and in setting the bases for future research perspectives in motor rehabilitation.

\section{Placebo modulation of force}

The main behavioral finding of our study is a placebo-induced enhancement of force in the experimental groups and a decrease in force-producing capacities in the control groups. Of note, both in the experimental groups and in one control group, the same TENS tool was applied, by using the same (inert) modality of stimulation. Therefore, we can exclude that differences in force between groups were to be ascribed to the type of peripheral stimulation. The decline of performance in the control groups could be explained by massed repetition of the task (Crupi et al., 2013) and by a physiological reduction of force, similar to what is commonly observed during physical training (Gandevia, 2001; Robbins et al., 2010). Interestingly, the placebo procedure reversed this behavioral pattern. The $\exp _{\text {verbal }+ \text { conditioning group was }}$ told that TENS had enhanced their force, and the conditioning procedure was applied to make them believe that TENS was really effective. Namely, by surreptitiously amplifying the cursor's excursion range, subjects of the $\exp _{\text {verbal }+ \text { conditioning group could see }}$ the cursor reaching higher lines of the target zone than before and were therefore conditioned about the effects of TENS in augmenting force. In our study, as in previous studies on the placebo effect (Montgomery and Kirsch, 1997; Benedetti et al., 2003; Colloca and Benedetti, 2006; Pollo et al., 2008), the conditioning was not considered as a mechanism, but as a procedure to induce expectation of better outcome. According to a cognitive interpretation of the classical conditioning (Rescorla, 1988), expectation is at the basis of learning in many situations. The higher scores at the expectation scale given by the $\exp _{\text {verbal + conditioning }}$ group compared with the control group certify that the conditioning procedure, together with verbal suggestion, induced to expect a better outcome. Moreover, the scores related to the perceived efficacy of TENS show that both experimental groups were convinced about its effects. This evidence suggests that the procedure was successful in inducing expectation of better motor performance and belief about the efficacy of the treatment, so that after the second TENS application the experimental groups achieved higher force levels. Interestingly, force enhancement was obtained even in the group of subjects who only received verbal instructions about the effects of TENS, without conditioning. The extent of enhancement, however, was not so pronounced as in the conditioned 

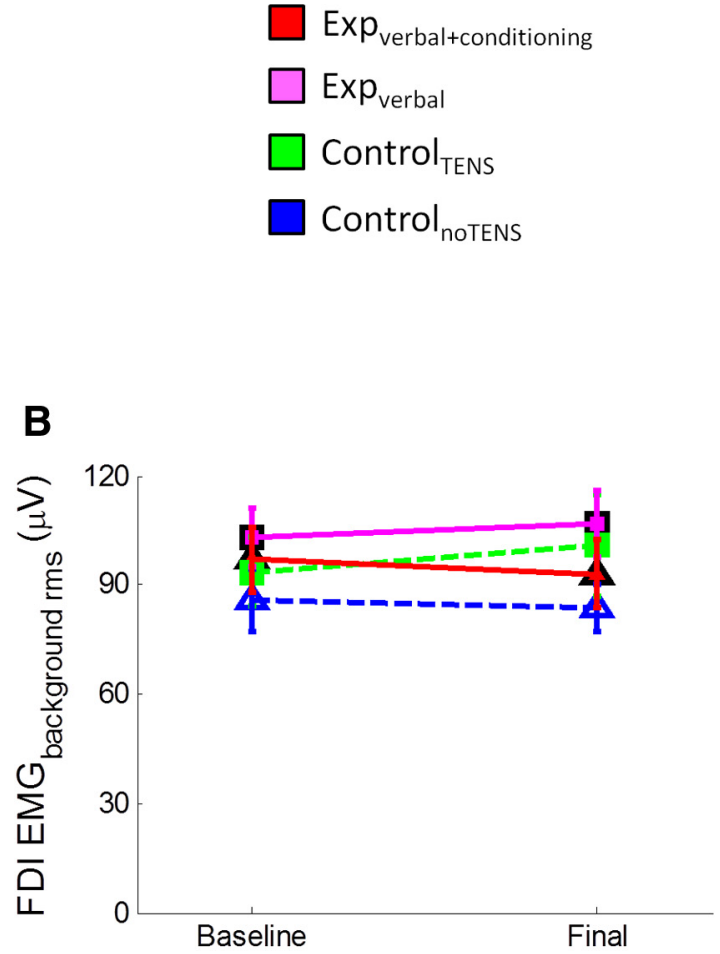

D

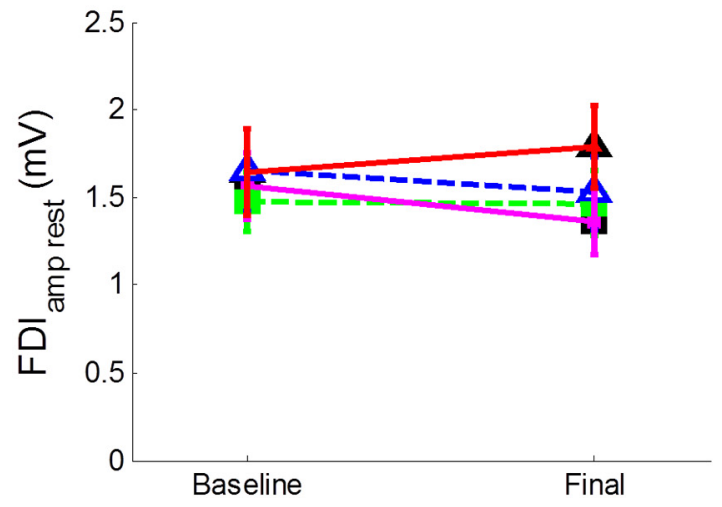

A

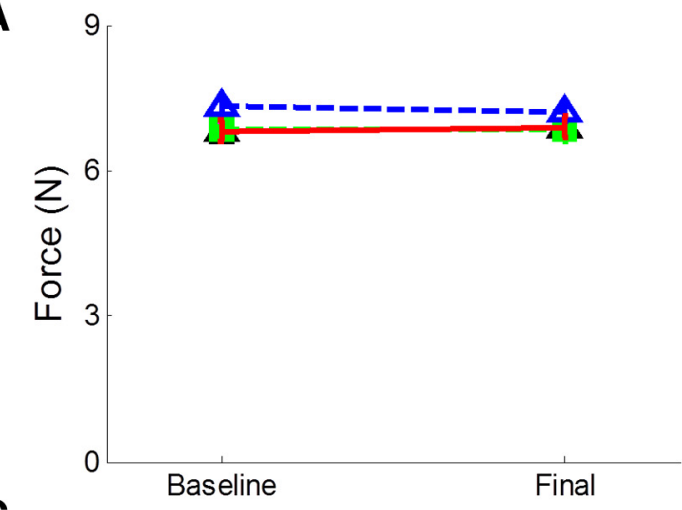

C

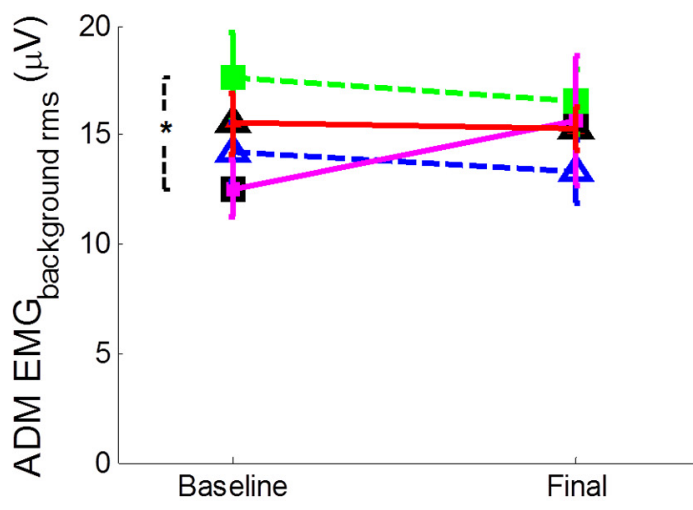

E

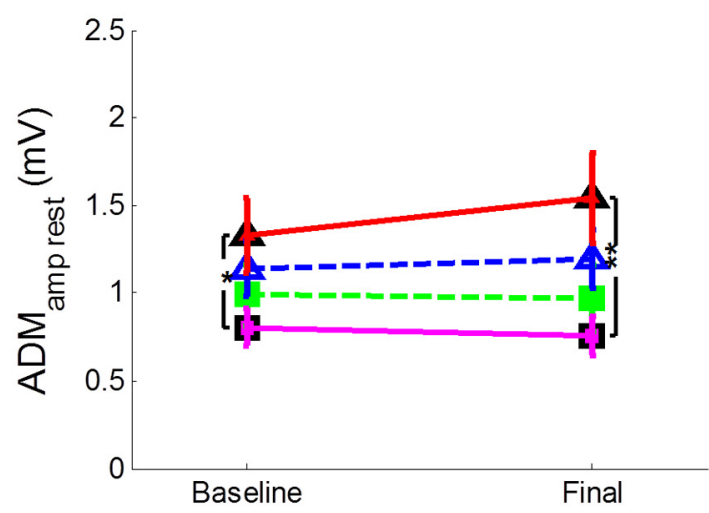

Figure 5. A, Illustration of the mean ( \pm SE) force level ( $N$ ) of the four groups of participants in the TMS task. This task was performed after the main motor task in the baseline and final sessions. The TMS pulse was delivered when participants kept the cursor on the red line (30\% MVF). Mean force level was computed from the onset of the trial until the delivery of the TMS pulse because TMS caused perturbation of the index finger pressure. As shown in the figure, the four groups exerted the same amount of force in this task, both in the baseline and final sessions. This suggests that the MEP amplitudes recorded during this task were not influenced by bottom-up factors, such as the amount of impressed force. $\boldsymbol{B}$, Mean ( \pm SE) EMG background activity (in microvolts) recorded from the FDI muscle before the TMS pulse. As shown in the figure, the four groups of participants had the same amount of EMG activation before MEP onset, both in the baseline and final sessions, suggesting that the MEP amplitude was not influence by the preceding EMG activity. C, Mean ( \pm SE) EMG background activity (in microvolts) recorded from the ADM muscle before the TMS pulse. This muscle was not involved in the task; and, as shown in the figure, the amount of EMG activation was very low and comparable in the four groups of participants. $\boldsymbol{D}$, Mean ( \pm SE) MEP amplitude (millivolts) recorded at rest from the FDI muscle. As shown in the figure, the four groups of participants display the same amplitude both in the baseline (before starting the experiment) and final session (after completing the experiment). This suggests that the change in corticospinal excitability does not generalize at the rest condition. $E$, Mean ( \pm SE) MEP amplitude (millivolts) recorded at rest from the ADM muscle. Results were the same as obtained from the FDI muscle.

group. This is in line with the notion that placebo effects are stronger after a conditioning procedure than with verbal suggestion alone (Colloca et al., 2008). A similar finding suggests that expectation of good motor performance may be sufficient to induce higher force levels, but the presence of a potentially rewarding positive visual feedback (as delivered during the conditioning phase) may influence performance even more, probably by enacting reward mechanisms (Lutz et al., 2012) that reinforce expectation.
This behavioral effect was robust in that it was observed both for the normalized force peak and for the percentage of strong pressures. These two behavioral indices highlight two slightly different aspects of performance: whereas the normalized force peak refers to the overall performance in relation to the maximum voluntary force and could potentially result from few very strong pressures among many weak pressures, the percentage of strong pressures is a more fine-tuned picture of the consistency of behavior and refers to the number of times in 

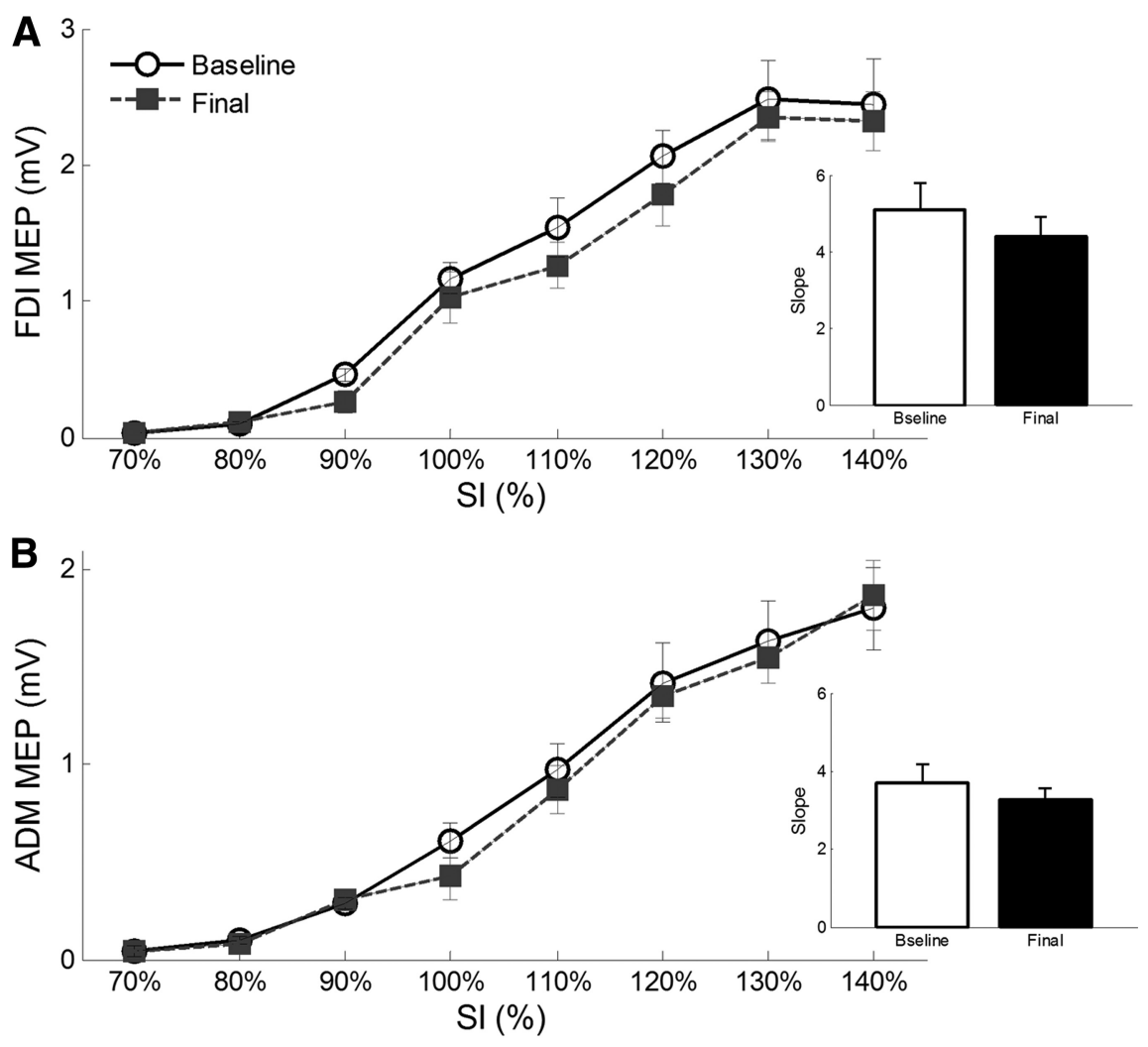

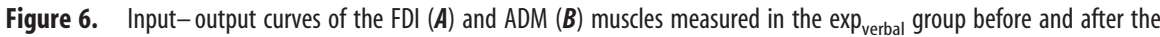
experimental procedure. Mean ( \pm SE) MEP amplitude of the two muscles are represented for different intensities of stimulation (in percentage of SI). As shown, MEP amplitudes progressively increase with higher stimulus intensities, but no change has been found between the baseline and final sessions. Right small panels, Mean ( $\pm \mathrm{SE}$ ) slope values are represented for the FDI and ADM muscles in the baseline and final sessions. Again, no difference was found across sessions.

which a subject consistently presses the piston above a certain threshold value.

Placebo procedures can enhance endurance in sport cyclists (Beedie et al., 2006), runners (Foster et al., 2004), and even nonathletes, untrained subjects (Benedetti et al., 2007; Pollo et al., 2008). In a pathological context, it is possible to speed up movement execution in patients with Parkinson's disease (Benedetti et al., 2004; Keitel et al., 2013). Here we demonstrate that one session is sufficient to exert observable placebo effects on force production, suggesting that this procedure may rapidly push forward the physiological strength limit that, with common resistance trainings, requires several weeks to be achieved (Carroll et al., 2002).

\section{The neurophysiological underpinnings of the placebo effect in the motor system}

With the neurophysiological investigation, we aimed at unveiling whether the placebo procedure could impact not only on force production, but also on the excitability of the corticospinal system. We found a dissociated pattern of corticospinal excitability in the experimental and control groups, with a clear increase in the former and a slight reduction in the latter. The MEP reduction in the control ${ }_{\text {noTENS }}$ group is in line with the reduced performance at the motor task and could be related to attentional decrease and mental fatigue (Conte et al., 2007; Crupi et al., 2013). In the control ${ }_{\text {TENS }}$ group, instead, MEP amplitude did not significantly decrease, probably because the mere TENS application, although not effective, prevented reduction of attention, thus maintaining MEP size stable (Conte et al., 2007). The fact that MEPs at rest (i.e., in the relaxed muscles), did not change throughout the sessions rules out the involvement of muscular fatigue (Taylor and Gandevia, 2001).

More interestingly, after the placebo procedure, we found enhanced corticospinal excitability in the experimental groups, as revealed by higher MEP amplitude, both in the $\exp _{\text {verbal }+ \text { conditioning }}$ and the $\exp _{\text {verbal }}$ groups, and shorter CSP duration, only in the exp verbal+conditioning group. This finding was exclusively obtained for the FDI, suggesting that the enhanced excitability is selective for the muscle specifically involved in the task at hand. Moreover, the increased excitability of the FDI was observed only in the active condition and not at rest, suggesting that it emerges only when force is required. This effect was not related to the intensity of TMS stimulation because, even at high intensities (i.e., $130 \%$ and $140 \%$ of SI in the I/O curve), MEPs at rest did not change across sessions. Furthermore, this effect was not trivially the result of bottom-up factors, such as the overall stronger pressure exerted by the experimental groups in the final session of the motor task. Namely, the TMS pulse was delivered at a time in which all the groups exerted the same amount of force (i.e., $30 \%$ of MVF) with a stable finger's position. Therefore, if we exclude peripheral, bottom-up factors as possible causes of the neurophysiological finding, we may conclude that the enhanced corticospinal excitability is the result of top-down, cognitive processes (i.e., expectation of better outcome and belief of treatment efficacy) and may represent the neural signature of a placebo effect in the motor system.

The two neurophysiological parameters that we considered (MEP and CSP) refer to different circuits and are generated by different mechanisms (Classen and Benecke, 1995; Hallett, 1995). Whereas the size of the MEP can be influenced by the activity of both cortical and spinal neurons (Rösler and Magistris, 2008), the CSP is mainly generated by motor cortical inhibition (Inghilleri et al., 1993; Wolters et al., 2008). The higher MEP amplitude in both experimental groups hints at an overall increased excitability of the corticospinal system. As regards the CSP duration, although a slight shortening could be observed in the $\exp _{\text {verbal }}$ group from baseline to final, it did not significantly change across sessions, suggesting that the modulation of the inhibitory cortical circuits was less pronounced in this group than in the $\exp _{\mathrm{verbal}+\text { conditioning }}$ group.

Existing evidence about the neural underpinnings of placebo modulations in motor performance derives from studies in Parkinson's disease (de la Fuente-Fernández et al., 2001; Pollo et al., 2002; Benedetti et al., 2004; Lidstone et al., 2010). Our study appears to represent the first direct demonstration that placebo can rapidly modulate the excitability of the corticospinal system in physiological conditions. Differently from previous studies, we devised a task in which force production was the main performance outcome. We speculate that the placebo procedure induced expectation of better performance and increased the 
voluntary drive to the motor cortex, thus resulting in enhanced corticospinal excitability.

Different cognitive functions can modulate the corticospinal system, such as reward processing (Klein et al., 2012), expectancy of a response signal (van Elswijk et al., 2007), emotional elaboration (Oliveri et al., 2003), and observation of other people's actions (Fadiga et al., 1995). The novelty of our study is to highlight the effects of a placebo procedure in rapidly changing the excitability of the corticospinal system. This finding hints at the powerful influence of suggestion on the motor system and could have implications in rehabilitation settings, as a leverage to potentiate the effects of the traditional treatments. Stimulating expectations of good performance and prompt recovery may not only trigger a more collaborative attitude in the patients but also exploit their residual neural resources, enhancing the ability to relearn adaptive patterns of motor activation.

\section{References}

Alaerts K, Senot P, Swinnen SP, Craighero L, Wenderoth N, Fadiga L (2010) Force requirements of observed object lifting are encoded by the observer's motor system: a TMS study. Eur J Neurosci 31:1144-1153. CrossRef Medline

Beedie CJ, Foad AJ (2009) The placebo effect in sports performance: a brief review. Sports Med 39:313-329. CrossRef Medline

Beedie CJ, Stuart EM, Coleman DA, Foad AJ (2006) Placebo effects of caffeine on cycling performance. Med Sci Sports Exerc 38:2159-2164. CrossRef Medline

Benedetti F, Pollo A, Lopiano L, Lanotte M, Vighetti S, Rainero I (2003) Conscious expectation and unconscious conditioning in analgesic, motor, and hormonal placebo/nocebo responses. J Neurosci 23:4315-4323. Medline

Benedetti F, Colloca L, Torre E, Lanotte M, Melcarne A, Pesare M, Bergamasco B, Lopiano L (2004) Placebo-responsive Parkinson patients show decreased activity in single neurons of subthalamic nucleus. Nat Neurosci 7:587-588. CrossRef Medline

Benedetti F, Pollo A, Colloca L (2007) Opioid-mediated placebo responses boost pain endurance and physical performance: is it doping in sport competitions? J Neurosci 27:11934-11939. CrossRef Medline

Borg G (1970) Perceived exertion as an indicator of somatic stress. Scand J Rehab Med 2:92-98. Medline

Brasil-Neto JP, Cohen LG, Panizza M, Nilsson J, Roth BJ, Hallett M (1992) Optimal focal transcranial magnetic activation of the human motor cortex: effects of coil orientation, shape of the induced current pulse, and stimulus intensity. J Clin Neurophysiol 9:132-136. CrossRef Medline

Butler JE, Petersen NC, Herbert RD, Gandevia SC, Taylor JL (2012) Origin of the low-level EMG during the silent period following transcranial magnetic stimulation. Clin Neurophysiol 123:1409-1414. CrossRef Medline

Carroll TJ, Riek S, Carson RG (2002) The sites of neural adaptation induced by resistance training in humans. J Physiol 544:641-652. CrossRef Medline

Clark VR, Hopkins WG, Hawley JA, Burke LM (2000) Placebo effect of carbohydrate feedings during a 40-km cycling time trial. Med Sci Sports Exerc 32:1642-1647. Medline

Classen J, Benecke R (1995) Inhibitory phenomena in individual motor units induced by transcranial magnetic stimulation. Electroencephalogr Clin Neurophysiol 97:264-274. CrossRef Medline

Colloca L, Benedetti F (2006) How prior experience shapes placebo analgesia. Pain 124:126-133. CrossRef Medline

Colloca L, Tinazzi M, Recchia S, Le Pera D, Fiaschi A, Benedetti F, Valeriani M (2008) Learning potentiates neurophysiological and behavioral placebo analgesic responses. Pain 139:306-314. CrossRef Medline

Conforto AB, Ferreiro KN, Tomasi C, dos Santos RL, Moreira VL, Marie SK, Baltieri SC, Scaff M, Cohen LG (2010) Effects of somatosensory stimulation on motor function after subacute stroke. Neurorehabil Neural Repair 24:263-272. CrossRef Medline

Conte A, Gilio F, Iezzi E, Frasca V, Inghilleri M, Berardelli A (2007) Attention influences the excitability of cortical motor areas in healthy humans. Exp Brain Res 182:109-117. CrossRef Medline

Coxon JP, Stinear CM, Byblow WD (2006) Intracortical inhibition during volitional inhibition of prepared action. J Neurophysiol 95:3371-3383. CrossRef Medline

Crupi D, Cruciata G, Moisello C, Green PA, Naro A, Ricciardi L, Perfetti B, Bove M, Avanzino L, Di Rocco A, Quartarone A, Ghilardi MF (2013) Protracted exercise without overt neuromuscular fatigue influences cortical excitability. J Mot Behav 45:127-138. CrossRef Medline

de la Fuente-Fernández R, Ruth TJ, Sossi V, Schulzer M, Calne DB, Stoessl AJ (2001) Expectation and dopamine release: mechanism of the placebo effect in Parkinson's disease. Science 293:1164-1166. CrossRef Medline

Devanne H, Lavoie BA, Capaday C (1997) Input-output properties and gain changes in the human corticospinal pathway. Exp Brain Res 114:329-338. CrossRef Medline

Duclay J, Pasquet B, Martin A, Duchateau J (2011) Specific modulation of corticospinal and spinal excitabilities during maximal voluntary isometric, shortening and lengthening contractions in synergist muscles. J Physiol 589:2901-2916. CrossRef Medline

Fadiga L, Fogassi L, Pavesi G, Rizzolatti G (1995) Motor facilitation during action observation: a magnetic stimulation study. J Neurophysiol 73: 2608-2611. Medline

Foster C, Felker H, Porcari JP, Mikat RP, Seebach E (2004) The placebo effect on exercise performance. Med Sci Sports Exerc 36 [Suppl 5]:S171.

Gandevia SC (2001) Spinal and supraspinal factors in human muscle fatigue. Physiol Rev 81:1725-1789. Medline

Hallett M (1995) Transcranial magnetic stimulation: negative effects. Adv Neurol 67:107-113. Medline

Hasegawa Y, Kasai T, Tsuji T, Yahagi S (2001) Further insight into the taskdependent excitability of motor evoked potentials in first dorsal interosseous muscle in humans. Exp Brain Res 140:387-396. CrossRef Medline

Inghilleri M, Berardelli A, Cruccu G, Manfredi M (1993) Silent period evoked by transcranial stimulation of the human cortex and cervicomedullary junction. J Physiol 466:521-534. Medline

Keitel A, Wojtecki L, Hirschmann J, Hartmann CJ, Ferrea S, Südmeyer M, Schnitzler A (2013) Motor and cognitive placebo-/nocebo-responses in Parkinson's disease patients with deep brain stimulation. Behav Brain Res 250:199-205. CrossRef Medline

Kischka U, Fajfr R, Fellenberg T, Hess CW (1993) Facilitation of motor evoked potentials from magnetic brain stimulation in man: a comparative study of different target muscles. J Clin Neurophysiol 10:505-512. CrossRef Medline

Klein PA, Olivier E, Duque J (2012) Influence of reward on corticospinal excitability during movement preparation. J Neurosci 32:18124-18136. CrossRef Medline

Lidstone SC, Schulzer M, Dinelle K, Mak E, Sossi V, Ruth TJ, de la FuenteFernández R, Phillips AG, Stoessl AJ (2010) Effects of expectation on placebo-induced dopamine release in Parkinson disease. Arch Gen Psychiatry 67:857-865. CrossRef Medline

Lutz K, Pedroni A, Nadig K, Luechinger R, Jäncke L (2012) The rewarding value of good motor performance in the context of monetary incentives. Neuropsychologia 50:1739-1747. CrossRef Medline

Mercado R, Constantoyannis C, Mandat T, Kumar A, Schulzer M, Stoessl AJ, Honey CR (2006) Expectation and the placebo effect in Parkinson's disease patients with subthalamic nucleus deep brain stimulation. Mov Disord 21:1457-1461. CrossRef Medline

Mills KR, Boniface SJ, Schubert M (1992) Magnetic brain stimulation with a double coil: the importance of coil orientation. Electroencephalogr Clin Neurophysiol 85:17-21. CrossRef Medline

Mima T, Oga T, Rothwell J, Satow T, Yamamoto J, Toma K, Fukuyama H, Shibasaki H, Nagamine T (2004) Short-term high-frequency transcutaneous electrical nerve stimulation decrease human motor cortex excitability. Neurosci Lett 355:85-88. CrossRef Medline

Montgomery GH, Kirsch I (1997) Classical conditioning and the placebo effect. Pain 72:107-113. CrossRef Medline

Oliveri M, Babiloni C, Filippi MM, Caltagirone C, Babiloni F, Cicinelli P, Traversa R, Palmieri MG, Rossini PM (2003) Influence of the supplementary motor area on primary motor cortex excitability during movements triggered by neutral or emotionally unpleasant visual cues. Exp Brain Res 149:214-221. Medline

Pollo A, Torre E, Lopiano L, Rizzone M, Lanotte M, Cavanna A, Bergamasco B, Benedetti F (2002) Expectation modulates the response to subthalamic nucleus stimulation in Parkinsonian patients. Neuroreport 13: 1383-1386. CrossRef Medline

Pollo A, Carlino E, Benedetti F (2008) The top-down influence of ergogenic 
placebos on muscle work and fatigue. Eur J Neurosci 28:379-388. CrossRef Medline

Rescorla RA (1988) Pavlovian conditioning: it's not what you think it is. Am Psychol 43:151-160. CrossRef Medline

Ridding MC, McKay DR, Thompson PD, Miles TS (2001) Changes in corticomotor representations induced by prolonged peripheral nerve stimulation in humans. Clin Neurophysiol 112:1461-1469. CrossRef Medline

Robbins DW, Goodale TL, Docherty D, Behm DG, Tran QT (2010) The effects of load and training pattern on acute neuromuscular responses in the upper body. J Strength Cond Res 24:2996-3007. CrossRef Medline

Rosenkranz K, Kacar A, Rothwell JC (2007) Differential modulation of motor cortical plasticity and excitability in early and late phases of human motor learning. J Neurosci 27:12058-12066. CrossRef Medline

Rösler KM, Magistris MR (2008) The size of motor evoked potentials: influencing parameters and quantification. In: The Oxford handbook of transcranial stimulation (Wassermann EM, Epstein CM, Ziemann U, Walsh V, Paus T, Lisanby SH, eds), pp 77-89. Oxford: Oxford UP.

Rösler KM, Petrow E, Mathis J, Arányi Z, Hess CW, Magistris MR (2002) Effect of discharge desynchronization on the size of motor evoked potentials: an analysis. Clin Neurophysiol 113:1680-1687. CrossRef Medline

Säisänen L, Pirinen E, Teitti S, Könönen M, Julkunen P, Määttä S, Karhu J (2008) Factors influencing cortical silent period: optimized stimulus lo- cation, intensity and muscle contraction. J Neurosci Methods 169:231238. CrossRef Medline

Taylor JL, Gandevia SC (2001) Transcranial magnetic stimulation and human muscle fatigue. Muscle Nerve 24:18-29. CrossRef Medline

Taylor JL, Allen GM, Butler JE, Gandevia SC (1997) Effect of contraction strength on responses in biceps brachii and adductor pollicis to transcranial magnetic stimulation. Exp Brain Res 117:472-478. CrossRef Medline

Tinazzi M, Zarattini S, Valeriani M, Romito S, Farina S, Moretto G, Smania N, Fiaschi A, Abbruzzese G (2005a) Long-lasting modulation of human motor cortex following prolonged transcutaneous electrical nerve stimulation (TENS) of forearm muscles: evidence of reciprocal inhibition and facilitation. Exp Brain Res 161:457-464. CrossRef Medline

Tinazzi M, Farina S, Bhatia K, Fiaschi A, Moretto G, Bertolasi L, Zarattini S, Smania N (2005b) TENS for the treatment of writer's cramp dystonia: a randomized, placebo-controlled study. Neurology 64:19461948. CrossRef Medline

van Elswijk G, Kleine BU, Overeem S, Stegeman DF (2007) Expectancy induces dynamic modulation of corticospinal excitability. J Cogn Neurosci 19:121-131. CrossRef Medline

Wolters A, Ziemann U, Benecke R (2008) The cortical silent period. In: The Oxford handbook of transcranial stimulation (Wassermann EM, Epstein CM, Ziemann U, Walsh V, Paus T, Lisanby SH, eds), pp 91-102. Oxford: Oxford UP. 